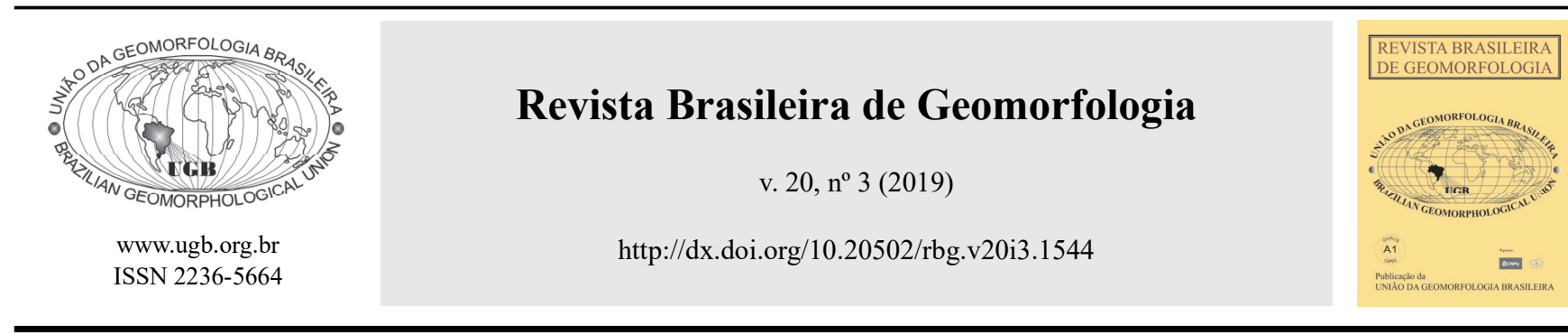

\title{
DINÂMICA DE MATÉRIA ORGÂNICA DE SUPERFÍCIE CONDICIONADA PELA TOPOGRAFIA EM FLORESTA ATLÂNTICA DE MACIÇO COSTEIRO, PARNA-TIJUCA, RJ
}

\author{
DYNAMICS OF SURFACE ORGANIC MATTER CONDITIONED BY \\ TOPOGRAPHY IN THE ATLANTIC FOREST OF THE COASTAL MASSIF, \\ PARNA-TIJUCA, RJ
}

Felipe Soter de Marize Miranda
Departamento de Geografia, Universidade Federal do Rio de Janeiro
Av. Athos da Silveira Ramos, 274, Rio de Janeiro, Rio de Janeiro. CEP 21941-916. Brasil
ORCID: 0000-0003-0008-4489
E-mail: felipesoter@yahoo.com.br

André de Souza Avelar

Departamento de Geografia, Universidade Federal do Rio de Janeiro Av. Athos da Silveira Ramos, 274, Rio de Janeiro, Rio de Janeiro. CEP 21941- 916. Brasil

ORCID: 0000-0003-4708-3803

E-mail:andre.avelar@globo.com

\section{Informações sobre o Artigo}

Recebido (Received):

25/05/2018

Aceito (Accepted):

24/06/2018

Palavras-chave:

Serapilheira; Gradiente

Topográfico; Geo-hidroecologia.

\section{Keywords:}

Litter; Topographic Gradient;

Geo-hydroecology

\section{Resumo:}

Em vista à importância da dinâmica de matéria orgânica para a ecologia florestal, o presente trabalho analisou a influência topografia sobre os processos de produção e estocagem de serapilheira em área de Floresta Atlântica Ombrófila pertencente ao PARNA-Tijuca, RJ. A pesquisa englobou aspectos da vegetação, a produção, redistribuição e estocagem de serapilheira, além de características do solo como presença de matéria orgânica e fertilidade. Tais variáveis foram comparadas entre as condições de divisor de drenagem, alta e baixa encostas e o fundo de vale. $\mathrm{O}$ divisor de drenagem destaca-se apresentando vegetação mais baixa, com dossel um pouco mais aberto, maior densidade de indivíduos e favorável às palmeiras, em comparação às demais áreas. As variações encontradas na estrutura da vegetação não se materializaram em diferenças significativas entre as posições na encosta em relação à massa de detritos orgânicos aportados ao solo durante um ano. A redistribuição de serapilheira pela topografia é essencialmente associada ao momento da queda dos detritos, e o material já depositado no solo também pode ser mobilizado para o movimento encosta abaixo. Condicionadas pelo gradiente de umidade vinculado à topografia, taxas de decomposição diferenciadas resultam em estoques de serapilheira significativamente menos espesso no fundo de vale onde a decomposição é mais rápida. $\mathrm{O}$ divisor de drenagem, menos úmido, apresenta estoque mais espesso. Os estoques foram similares e intermediários na alta e baixa encosta. Como provável reflexo da decomposição mais lenta da serapilheira, o divisor de drenagem apresentou pior condição de fertilidade, com alta acidez e presença de alumínio. 


\begin{abstract}
:
Given the importance of the organic matter dynamics to the forest ecology, this study examined the influence of topography on debris production and litter storage processes in hillside Atlantic Rain Forest, belonging to PARNATijuca, RJ. Aspects of the vegetation, litterfall, litter redistribution and storage, as well as soil characteristics, such as the presence of organic matter and fertility, were analyzed. These variables were compared between the conditions found in the summit, high and low hillsides and the bottom valley. The summit showed shorter vegetation, with a slightly open canopy, higher density of individuals and better opportunities to the palms trees, in comparison to the other areas. The variations found in vegetation structure do not materialized in significant differences in litterfall mass contributions to the ground for one year. The litter redistribution by topography is primarily associated with the moment of its fall, and the material already deposited in the soil can also be mobilized for the downhill movement. The moisture content in the litter increases in the downhill direction and seems to be the main factor responsible for the bottom valley presenting litter storage significantly lower than that observed in the summit. The litter cover was similar on the high and low hillsides. As a probable reflex of the slower litter decomposition, the summit presented worse fertility condition, with high acidity and the presence of aluminum.
\end{abstract}

\section{Introdução}

A dinâmica ecológica das Florestas Tropicais tem sido pesquisada em termos de sua relevância para os ciclos biogeoquímicos globais, principalmente, em relação à estocagem de carbono (C) dada pelo balanço entre os processos de síntese e decomposição da matéria orgânica (MO) (Siefert e Santos, 2018). Em escala local, a dinâmica de MO é também relevante ao desempenhar importantes funções na manutenção de ecossistemas naturais e outros serviços ambientais à sociedade.

Vivendo, geralmente, acima de solos altamente intemperizados, com baixa fertilidade natural pelo histórico de lixiviação de nutrientes em sua pedogênese, as Florestas Tropicais apresentam sua exuberância sustentada pela decomposição da necromassa depositada sobre o solo (serapilheira) e a consequente disponibilização dos nutrientes em dinâmica de ciclagem (Dick e Schumacher, 2015). A serapilheira acumulada sobre o solo forma uma camada que o protege contra a erosão, é habitat de diversas espécies de invertebrados e pode determinar as condições microambientais para a germinação de sementes (Marcos e Matos, 2003).

A decomposição da serapilheira é realizada por microorganismos especializados, resultando na mineralização de parte do $\mathrm{C}$ com a liberação de nutrientes. A fração da necromassa mais resistente à decomposição se acumula no solo na forma de húmus. O húmus contido no solo pode favorecer a retenção dos cátions nutritivos liberados pela decomposição além de ajudar a formação de agregados estáveis no solo, influenciando sua fertilidade e melhorando a capacidade de circulação de água e gases (Abdollahi et al., 2014). A proporção entre mineralização e acumulação de húmus é dada pela taxa de decomposição da serapilheira, por sua vez, controlada, basicamente, pela ação favorável da temperatura e umidade em associação à qualidade/resistência química do material (Swift et al., 1979). As modulações nos processos de produção e decomposição de $\mathrm{MO}$ em ambientes terrestres alteram os fluxos de nutrientes e energia aos corpos hídricos, afetando ecossistemas límnicos e a qualidade da água para o abastecimento humano (Camino-Serrano et al., 2014; Ye et al., 2015).

Embora a dinâmica de serapilheira seja objeto comum de estudo com ênfase na ciclagem de nutrientes, a maioria dos trabalhos não abarca a dinâmica de fluxos espaciais de detritos, mantendo uma abordagem que considera apenas o movimento vertical do material - aporte ao solo. A abordagem da dinâmica e heterogeneidade espacial da serapilheira ainda se concentra onde o degelo atua na redistribuição massiva de detritos, a exemplo dos trabalhos de Orndoff e Lang (1981) e Fahnestock et al., (2000). A utilização do estoque de serapilheira como indicador funcional ecológico em domínios tropicais, como visto nos trabalhos de Pessoa et al. (2012) e Santos et al. (2018), são de potencial interessante para diagnósticos funcionais rápidos sobre a integridade ecológica de fragmentos florestais. Contudo, variações espaciais naturais aos ecossistemas, como as associadas à topografia, se apresentam como ruídos nestas análises quando não conhecidas/esperadas.

Os remanescentes de Mata Atlântica encontram-se hoje, basicamente, restritos aos ambientes montanhosos, fato que ressalta a importância do conhecimento da influência do relevo acidentado sobre os processos 
ecológicos. As formas do relevo podem influenciar a composição florística local em termos das condições (micro)ambientais dada pelos fatores climáticos vinculados à altitude, assim como pelo condicionamento aos fluxos hídricos conformando um gradiente de disponibilidade de umidade no solo (Higuchi et al., 2012; Vale et al., 2017). Contudo, a forma como o gradiente de umidade vinculado à topografia pode influenciar as condições edáficas ao controlar a dinâmica espacial e de decomposição de MO ainda é pouco estudada. Esta linha de pesquisa pode ser uma contribuição importante para o conhecimento sobre a heterogeneidade espacial de processos ecológicos e pedológicos na Mata Atlântica.

Neste contexto, o presente trabalho objetivou analisar a dinâmica de serapilheira em área montanhosa de Mata Atlântica através de uma perspectiva espacial vinculada à topografia, trazendo à luz os processos de produção e redistribuição de detritos orgânicos e a heterogeneidade espacial de sua acumulação sobre o solo. A abordagem de uma condicionante hidrológica, tratada no presente trabalho como contexto geo-hidroecológico, se aproxima da hidrogeomorfologia (Goerl et al., 2012) acrescentada de um viés ecológico. $\mathrm{O}$ foco recaiu sobre a dinâmica de serapilheira, de forma que foram analisados atributos básicos da estrutura da vegetação apenas como subsídio para o entendimento da heterogeneidade espacial do aporte e acumulação de detritos.

Com o melhor entendimento acerca da heterogeneidade espacial dos estoques de serapilheira em um gradiente de encosta, pretende-se contribuir diretamente a pesquisas relacionadas à fitogeografia, à fitossociologia, às propriedades do solo e ao uso de indicadores funcionais na Mata Atlântica. Ademais, estudos hidrológicos costumam dar alguma ênfase ao potencial de retenção hídrica da serapilheira no balanço hidrológico de bacias hidrográficas florestadas, assim como estudos sobre ecossistemas límnicos são baseados, muitas vezes, nos fluxos de MO dos ambientes terrestres para os aquáticos, de forma que a lixiviação da serapilheira é sua principal fonte de MO (Seekell et al., 2015; Miranda e Avelar, 2017).

\section{Materiais e Métodos}

\section{1 Área de estudos}

O Estudo foi conduzido na Floresta da Tijuca, fragmento florestal circundado por uma matriz altamen- te urbanizada. A vegetação de Mata Atlântica recobre o Maciço da Tijuca $\left(22^{\circ} 55^{\prime}\right.$ e $23^{\circ} 00^{\prime} \mathrm{S}-4^{\circ} 20^{\prime}$ e $\left.43^{\circ} 10^{\prime} \mathrm{W}\right)$, uma das três unidades fisiográficas montanhosas do município do Rio de Janeiro, representantes do contexto dos Maciços Costeiros do sudeste brasileiro. O Maciço da Tijuca é um ambiente de relevo acidentado, marcado pela presença de afloramentos rochosos e encostas abruptas, com a presença de vários picos e pontões, alcançando altitude máxima de $1021 \mathrm{~m}$ (Pico da Tijuca).

O clima é tropical de altitude (cf), com temperatura média anual de $22^{\circ} \mathrm{C}$ e médias mensais oscilando entre 25 e $19^{\circ} \mathrm{C}$ em fevereiro e junho, respectivamente. A máxima pode chegar a $35^{\circ} \mathrm{C}$ no verão e a mínima a $10^{\circ} \mathrm{C}$ no inverno (Negreiros e Coelho Netto, 2011). A pluviosidade média anual oscila entre 2000 e 2500 $\mathrm{mm}$, podendo registrar até $3.300 \mathrm{~mm}$ em anos mais chuvosos, e $1600 \mathrm{~mm}$ nos menos chuvosos (Figueiró e Coelho Netto, 2007). No período de monitoramento da queda de detritos orgâncos (jan/2016-fev/2017), a chuva apresentou sazonalidade atípica para a área, com mais chuva do que o esperado no inverno, principalmente em Junho, e menor precipitação no verão, principalmente em janeiro (figura 1 ).

As rochas são do Proterozóico Superior e o embasamento litológico é formado, basicamente, por gnaisses diversos e algumas intrusões de granito. Predominam os latossolos, principalmente os vermelho-amarelos nas áreas de encosta, com cambissolos em áreas mais íngremes. A textura do solo no horizonte A é arenosa, variando entre Franco Arenosa e Areia Franca (Negreiros e Coelho Netto, 2011).

A vegetação é típica de Mata Atlântica secundária tardia, com a presença de espécies arbóreas exóticas e interferência antrópica inerente (Montezuma, 2005; Sales e Guedes-Bruni, 2017). A floresta que hoje é protegida pelo PARNA-Tijuca (3.972 ha) foi recuperada por ações de reflorestamento $(5,2 \%$ da área) e pelo processo de regeneração natural $(94,8 \%)$, após ser quase totalmente deflorestada para plantação do café até a metade do século XIX. Hoje, a área apresenta mais de 140 anos de sucessão natural em sua maior parte (Coelho Netto, 1987). As vertentes voltadas ao sul apresentam vegetação mais exuberante e menor presença campos de gramíneas, tanto por questões naturais (encostas soalheiras e noruegas), quanto por questões de ocupação e manejo (Oliveira et al., 1995; Dias e Coelho Netto, 2011). 


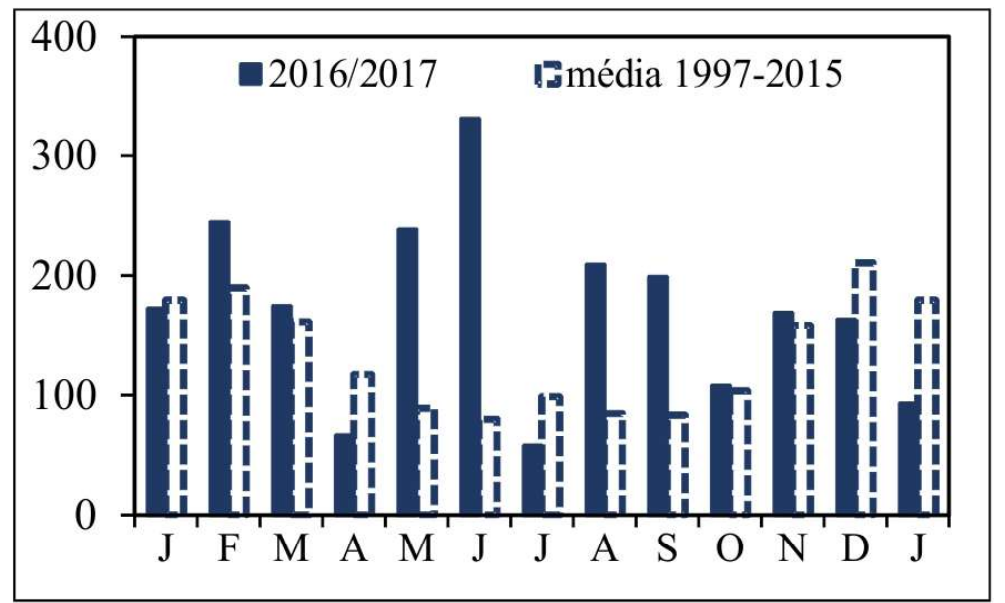

Figura 1 - Precipitação mensal de janeiro de 2016 a janeiro de 2017 e médias de precipitação mensais no período de 1977 a 2015.

\subsection{Espacialidade amostral}

Utilizou-se como encosta laboratório a vertente sul do Morro do Archer, localizada no alto curso do Rio Cachoeira e totalmente inserida nos domínios do PARNA-Tijuca (figura 2). Acredita-se que esta encosta seja representativa do contexto do Maciço da Tijuca e dos maciços costeiros em geral em relação à vegetação (composição e influência marítima) e condições morfológicas como declividade e ocorrência de pontões, picos e paredões rochosos (Fernandes et al., 2006). Trata-se de uma encosta de aproximadamente $550 \mathrm{~m}$ de extensão do divisor de drenagem ao fundo de vale (Rio do Archer), com altitude entre 700 e $550 \mathrm{~m}$. A escala espacial reduzida do presente trabalho procurou o isolamento de condições ambientais de outra natureza que não o gradiente topográfico.

$\mathrm{O}$ estudo foi realizado em duas etapas, as quais tiveram espacialidade de coletas distintas:

( $1^{\mathrm{a}}$ etapa) Análise da influência da topografia para redistribuição espacial de serapilheira. Nesta etapa foram definidas 03 áreas de coletas de dados em diferentes posições na encosta: uma no Divisor de Drenagem (DV); outra na Meia Encosta (ME); e a terceira no Fundo de Vale (FV). Em cada uma destas posições na encosta foram estabelecidas duas subáreas/parcelas $(10 \times 10 \mathrm{~m})$ para a aquisição de dados, sendo uma plana $(\mathrm{P})$, com declividade entre 0 e $10^{\circ}$, e a outra íngreme (I), com declividade entre 30 e $40^{\circ}$. Ou seja, as coletas desta etapa foram realizadas em 06 parcelas distribuídas em três posições na encosta, denominadas: DV-P; DV-I; ME-P; ME-I; FV-P; e FV-I.

( $2^{\mathrm{a}}$ etapa) Caracterização do gradiente de vegetação e de estocagem de serapilheira ao longo da encosta. Ampliou-se o número de posições na encosta analisadas, substituindo-se a ME por duas novas áreas: Alta Encosta (AE) e a Baixa Encosta (BE). As posições DV e FV foram mantidas. A intenção de manter certa equidistância entre as posições resultou na não manutenção da área $\mathrm{ME}$, dada a proximidade desta às novas áreas: $\mathrm{AE}$ e BE. Nesta $2^{\mathrm{a}}$ etapa não houve subdivisão das áreas em íngremes e planas, sendo os dados coletados em parcelas (20x15 m) estabelecidas uma em cada posição da encosta.

Em todas as demarcações evitou-se as linhas/ eixos de concavidade que se manifestam como canais de drenagem efêmeros na encosta, onde há uma grande quantidade de blocos de rocha depositados. Foi notável, em observação de campo, que tais condições ocorrem em sulcos de 02 a $03 \mathrm{~m}$ de largura com reflexo sobre a estrutura da vegetação - a formação de escoamentos superficiais temporários inibe a germinação de sementes ou crescimento das plântulas.

Um experimento com folhas marcadas, mensurações acerca do deslocamento lateral de detritos e do conteúdo de umidade contida na serapilheira ocorreram em três posições na encosta: DV; ME; e FV ( $1^{\text {a }}$ etapa) nas 06 subáreas. Adicionalmente, o aporte de detritos orgânicos também foi contabilizado nestas subáreas, porém, estes resultados foram utilizados apenas para a discussão dos resultados de deslocamento lateral. Ainda nestas três posições na encosta foram coletadas amostras de solo para análises químicas acerca da fertilidade. Contudo, a coleta de solo não foi realizada com base nas 06 subáreas - detalhes no subítem 2.9. 


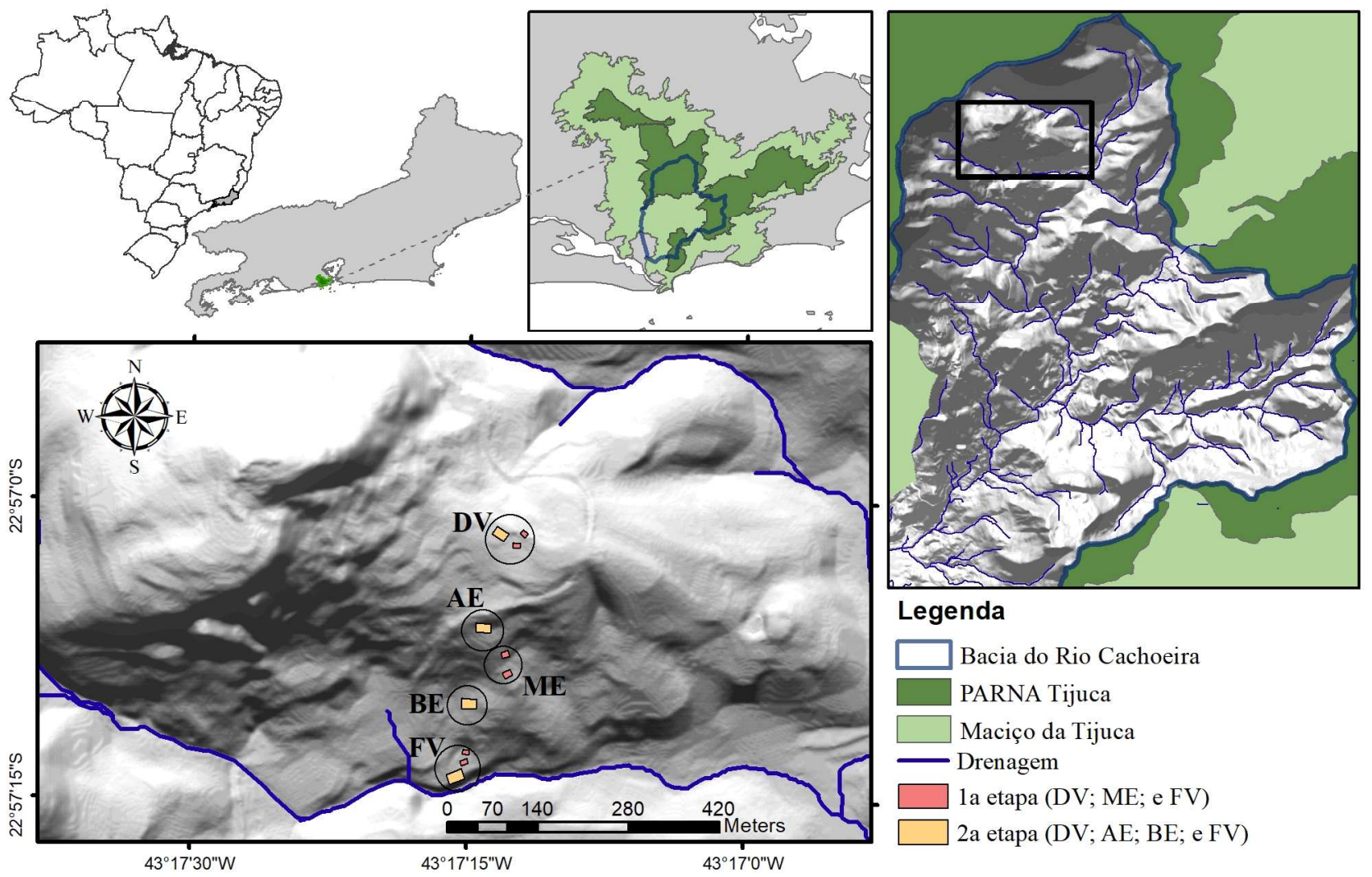

Figura 2 - Localização da Encosta sul do Morro do Archer e das áreas de coleta no contexto do Maciço da Tijuca sobre um Modelo Digital do Terreno elaborado a partir de mapeamento LiDAR trabalhado em Miranda et al. (2014). As áreas de coleta da $1^{a}$ etapa consistem em 02 subáreas/parcelas: íngreme e plana.

Em continuidade à pesquisa, um levantamento da estrutura da vegetação, do aporte anual de detritos orgânicos ao solo e análises de massa e estrutura dos estoques de serapilheira foram realizados em quatro posições da

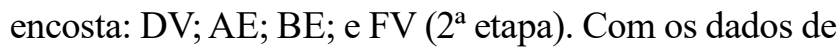
produção anual e estocagem de serapilheira, calculou-se o coeficiente de deposição K' (Olson, 1968) para cada área, dado pela razão entre produção e estoque $(\mathrm{K}=\mathrm{P} / \mathrm{E})$.

\subsection{Levantamento da estrutura da vegetação}

Foi realizado nas áreas da $2^{\mathrm{a}}$ etapa $(\mathrm{DV} ; \mathrm{AE} ; \mathrm{BE}$; $\mathrm{FV}$ ) em parcelas de $300 \mathrm{~m}^{2}$ (20x15 m). Em campo mediu-se o perímetro à altura do peito (PAP) das árvores e foi contabilizado o número de árvores mortas e de palmeiras. A partir do PAP foi calculado o diâmetro à altura do peito (DAP). Também foram calculadas a densidade de indivíduos por hectare (ind.ha ${ }^{-1}$ ) e a área basal (G), esta dada pelo somatório da secção horizontal do tronco de todos os indivíduos, extrapolada para um hectare $\left(\mathrm{m}^{2} \cdot \mathrm{ha}^{-1}\right)$. Considerou-se para as análises apenas indivíduos com DAP $\geq 05 \mathrm{~cm}$.
Não foi realizada a identificação de espécies ou de outros níveis taxonômicos. Contudo, foram contabilizados indivíduos da família Aracaceae (palmeiras), uma vez que a presença de tal família pode ser utilizada como indicador de estágio sucecional ou de outras condições ambientais (Marcos e Matos, 2003; Stefani, 2017). Adicionalmente, a presença de uma espécie da família Aracaceae, a Euterpe edulis, foi relatada por anotações de campo e de laboratório (não foram contabilizados indivíduos) para as áreas e ocasiões onde ocorriam em abundância suas sementes na serapilheira, as quais são facilmente identificáveis (açaí), em vista a fortalecer a discussão dos resultados.

Foi estimada a altura das árvores em campo objetivando a análise da estratificação e altura de estratos inferiores do dossel. A altura do estrato superior foi discutida frente ao exposto em Miranda et al., (2014), onde foi apresentado um Modelo Digital de Altura de Árvores para a encosta, extraído de mapeamento LiDAR (Light Detection And Ranging) na área. 
Foi analisada a abertura do dossel com o uso de fotografias: cada área foi dividida ao meio $(10 \times 15 \mathrm{~m}) \mathrm{e}$ do ponto central de cada meia área foi tirada uma foto de baixo ( $\cong 1,8 \mathrm{~m}$ do chão) para cima (dossel). As fotos foram binarizadas em preto e branco no software ArcGis 10 de forma que o branco representasse a abertura e o preto a cobertura do dossel. A contagem foi feita por amostragem de pixels e calculada em percentuais de abertura de cada posição na encosta, dada pela média entre os resultados das duas fotografias.

\subsection{Queda de detritos orgânicos}

Este parâmetro consiste na queda de detritos vegetais que vão compor a serapilheira sobre o solo durante um intervalo de tempo. Na $1^{\mathrm{a}}$ etapa da pesquisa foi realizado procedimento idêntico ao descrito a seguir, porém, seus dados foram utilizados apenas para a discussão sobre o deslocamento lateral de serapilheira, uma vez que descreveu período curto (16 semanas). A avaliação do aporte anual (de fevereiro de 2016 a janeiro de 2017) foi realizado na $2^{a}$ etapa de pesquisa, quando foram instalados 05 coletores circulares em cada posição na encosta (DV; AE; BE; FV), com abertura de 0,265 $\mathrm{m}^{2}$ cada coletor, totalizando $1,33 \mathrm{~m}^{2}$ amostrados por área. $\mathrm{O}$ material coletado foi retirado mensalmente dos coletores e transportado para laboratório onde foi secas em estufa do tipo Secagem e Esterilização da marca Solab, a $65^{\circ} \mathrm{C}$ até peso constante, e triado em relação aos tecidos: material foliar (MF), materiais lenhosos (ML) e tecidos reprodutivos (MR). Após a triagem, cada fração foi pesada e o valor transformado para toneladas

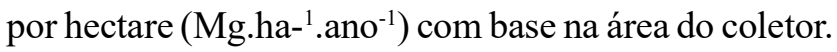

\subsection{Deslocamento lateral de serapilheira}

Esta análise permitiu avaliar a capacidade da topografia em realocar detritos orgânicos. Tal observação é rara na literatura nacional e representa uma base interessante para a discussão sobre a dinâmica de MO em ambientes declivosos. Em cada uma das 06 subáreas da $1^{\mathrm{a}}$ etapa (subitem 2.2) foram montados 03 coletores constituídos de uma pequena trincheira de 1,0 m de extensão, cavada transversal ao declive, com $0,5 \mathrm{~m}$ de largura e $0,3 \mathrm{~m}$ de profundidade. A trincheira foi coberta com tela de nylon (01 $\mathrm{mm}$ de abertura), e uma base de PVC $(0,5 \mathrm{~m}$ de altura) mantinha somente a lateral voltada à montante aberta. Uma tela de alumí- nio (04 $\mathrm{mm}$ de abertura) mantinha o material erguido $( \pm 15 \mathrm{~cm})$ para evitar que ficasse em contato com o solo. O material capturado foi retirado semanalmente (acumulado de 01 semana de captura) por 16 semanas (08/04 - 29/07 de 2013), seco em estufa do tipo Secagem e Esterilização, a $65^{\circ} \mathrm{C}$ até peso constante, triado pelo tipo de tecido (MF, ML, MR) e cada fração pesada. Os dados foram considerados como atravessamento linear $\left(\mathrm{g} . \mathrm{m}^{-1}\right)$, sem o conhecimento da área de origem do material, exceto aquele originado pelo experimento com folhas marcadas.

\subsection{Experimento com folhas marcadas}

Este procedimento avaliou a possibilidade de folhas já depositadas no piso florestal serem mobilizadas ao movimento encosta abaixo. Em cada uma das subáreas íngremes da $1^{\mathrm{a}}$ etapa (DV-I; ME-I; FV-I) foram posicionadas sobre o solo folhas pintadas de cor laranja luminoso, todas retiradas da produção das respectivas áreas. Estas continham inscrições com a distância que estavam da entrada dos coletores de deslocamento lateral, distribuídas em linha reta paralela ao declive: $01,03,05,10$ e $15 \mathrm{~m}$. O objetivo foi identificar a distância de onde algumas folhas vieram no caso de serem capturadas em tais coletores. Cada área recebeu 15 folhas marcadas, distribuídas com um conjunto de folhas (diferentes distâncias) alinhado com cada um dos 03 coletores.

Este experimento não previa um tempo determinado de operação e foi iniciado no dia 13/05/2013, quando as folhas foram posicionadas no piso florestal. O objetivo foi capturar alguma(s) nos coletores de movimento encosta abaixo no ato das coletas semanais. A impossibilidade de identificar as folhas sobre o solo, por conta de sua "vida útil" (tempo em que a folha mantinha sua integridade física) ou seu deslocamento encosta abaixo, ditariam o tempo de experimento. As folhas foram facilmente avistadas onde foram depositadas por 04 semanas.

\subsection{Estoque de serapilheira sobre o solo}

$\mathrm{O}$ estoque de serapilheira foi coletado em dois períodos diferentes: final do inverno (2016) e final do verão (2017) utilizando-se um quadrado de madeira de $25 \times 25 \mathrm{~cm}$, colocado sobre o solo no momento da coleta. Ao todo, em cada uma das áreas da $2^{\mathrm{a}}$ etapa da pesquisa 
(DV; AE; BE; e FV) foram coletadas 06 amostras de serapilheira, 03 em cada período. Foi avaliada a variação sazonal pela comparação entre os dois períodos, e considerado como estoque anual o valor médio entre estes.

Para evitar-se a coleta em área pisoteada no processo de pesquisa, foi isolada ao acesso uma faixa de área $(0,5 \times 10 \mathrm{~m})$ adjacente e a montante da parcela de estrutura da vegetação. Estas áreas foram posicionadas a montante das parcelas para não receberem material empurrado encosta abaixo pelo pisoteio dentro da parcela. A existência de blocos de rocha, raízes, árvores e arvoretas dificultou a adoção de um método aleatorizado para o posicionamento de coleta nesta faixa. Assim sendo, foi adotada coleta no sentido oeste-leste a partir da borda oeste da faixa (inverno), e no sentido leste-oeste (verão), a partir da borda leste, mantendo-se uma distância mínima de $01 \mathrm{~m}$ entre os pontos de coleta e da borda lateral da faixa.

$\mathrm{Na}$ área interna do quadrado de madeira foi retirado todo o material visivelmente orgânico, incluindo alguma quantidade de partículas minerais. O material coletado foi seco em estufa, do tipo Secagem e Esterilização, a $65^{\circ} \mathrm{C}$ até peso constante, e triado em folhas íntegras, denominadas de folhas lavadas (FL), em folhas fragmentadas (FF), materiais lenhosos (ML) e materiais reprodutivos (MR), de forma similar ao proposto em Garay et al. (2003). O procedimento de triagem foi realizado sobre peneira de $02 \mathrm{~mm}$, e tanto o material mineral retido na peneira, quanto os orgânicos e minerais $<02$ $\mathrm{mm}$, foram descartados. O material triado foi pesado e seu peso em gramas transformado em toneladas por

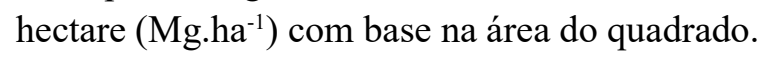

\subsection{Conteúdo de umidade na serapilheira}

Em cada uma das áreas da $1^{\mathrm{a}}$ etapa (AE; ME; e FV) foram coletadas 16 amostras (01 por semana, de 08/04 a 29/07 de 2013) de serapilheira, utilizando-se o mesmo quadrado de madeira citado no subitem anterior, para a avaliação da água retida na serapilheira. Para tanto, as amostras foram colocadas, ainda em campo, em sacos plásticos especiais que podem ser aquecidos. Em laboratório as amostras foram pesadas antes da secagem (peso úmido) e, posteriormente, as amostras foram abertas e secas em estufa do tipo Secagem e Esterilização, a $65^{\circ} \mathrm{C}$ até peso constante. $\mathrm{O}$ peso seco foi subtraído do peso úmido e a diferença considerada como o teor gravimétrico de umidade da amostra. Por fim, esse valor de massa de água foi ponderado em valores percentuais frente ao peso seco de cada amostra.

Não foi realizada uma análise temporal da umidade contida na serapilheira, com a discussão dos resultados semanais frente ao contexto pluviométrico. A análise foi feita, exclusivamente, de forma comparativa entre as posições na encosta, considerando-se que todas as posições estavam expostas às mesmas condições pluviométricas. Apoia-se tal ideia na proximidade espacial entre as áreas e no fato das amostras serem coletadas, sempre, no mesmo dia em todas as posições na encosta.

\subsection{Análises de fertilidade de solo}

Em cada área da $1^{\mathrm{a}}$ etapa (DV; ME; FV) foram coletadas 09 amostras deformadas do solo, coletadas entre 05 e $15 \mathrm{~cm}$ de profundidade, perfazendo uma composta para cada posição na encosta. A distribuição espacial das coletas dentro de cada posição da encosta foi dada por 03 amostras na subárea plana, 03 na subárea íngreme e 03 amostras distância entre tais. Foi coletado sempre mais de $100 \mathrm{~g}$ de solo e as amostras foram enviadas à EMBRAPA como terra fina seca ao ar, onde foram realizadas as análises químicas de rotina $(\mathrm{pH}, \mathrm{P}, \mathrm{K}, \mathrm{Ca}$, $\mathrm{Mg}, \mathrm{Al}, \mathrm{H}+\mathrm{Al}$ ) acrescida da análise de conteúdo de $\mathrm{C}$ orgânico. Os cálculos da soma de bases (S), capacidade de troca catiônica total em pH 7,0 (T) e da saturação de bases $(\mathrm{V})$, foram realizados segundo o Manual de Análises de Solo da EMBRAPA (1997).

\subsection{Análises Estatísticas}

Todos os valores médios apresentados tiveram o cálculo de seus respectivos desvios padrão e foram comparados com o teste de variância não paramétrico Kurskal-Wallis (K-W), considerada a variação significativa quando a probabilidade de hipótese nula $(p)$ foi menor que 0,05 . Quando ocorreu significativa variância, foi utilizado o teste Dunn a posteriori em situação de mais de duas populações de dados em comparação. Adicionalmente, alguns dados foram analisados com correlação linear de Pearson $(R)$ ou regressões $\left(R^{2}\right)$.

Os dados sobre a sazonalidade e o estoque anual de serapilheira de cada área foram analisados por uma ANOVA em Blocos casualizados, considerando-se as coletas de cada estação (inverno e verão) como os tratamentos replicados dentro das diferentes áreas (blocos) (Gotelli e Ellison, 2011). Também foi utilizado 
o delineamento em blocos casualizados para a análise dos dados de deslocamento lateral de serapilheira, neste caso, considerando-se a condição de declividade (íngeme e plano) como os tratamentos replicados nas diferentes posições na encosta (DV; ME; e FV). Ainda sobre esta análise, os três coletores de deslocamento lateral de cada parcela conformaram uma média para cada respectiva subárea, e os resultados apresentados representam o somatório dos valores obtidos nas 16 semanas de coleta de material, ou seja, o valor médio $(n=3)$ do acumulado de 16 semanas.

\section{Resultados e Discussão}

\subsection{Estrutura da vegetação e aporte de detritos orgânicos na encosta}

Foram contabilizados 241 indivíduos arbóreos em $1200 \mathrm{~m}^{2}$ amostrados na encosta, o que equivale a uma densidade de 2008 ( \pm 494) ind.ha ${ }^{-1}$. A área basal média obtida no presente levantamento (tabela 1 ) encontra-se acima do geralmente reportado para as Florestas Ombrófilas no sudeste do Brasil (Guedes e Kuprek, 2016; Silva et al., 2018). Este resultado foi influenciado pelo alto valor de área basal no DV, posição na encosta que apresentou a maior densidade de indivíduos e o maior DAP observado ( $2^{\circ}$ maior DAP médio), mesclando alta densidade e a ocorrência de alguns indivíduos de grande porte. Observada a tendência de redução da densidade de indivíduos no sentido encosta abaixo, nas demais posições à jusante na vertente (AE; $\mathrm{BE}$; e FV), as menores densidades limitaram os valores de área basal até patamares mais típicos das Florestas Ombrófilas do sudeste brasileiro: entre 30 e $50 \mathrm{~m}^{2}$.ha ${ }^{-1}$ (Guedes-Bruni, 1998; Carvalho et al., 2005; Ritter, 2016).

Apesar de possuir a menor densidade de indivíduos, o FV apresentou a segunda maior área basal em virtude da maior presença de indivíduos de DAP elevado (figura 3), sendo a posição na encosta com o maior DAP médio das árvores. A área do DV é a única que não apresentou a distribuição de indivíduos por classe de DAP conhecida como J-invertido, caracterizada pela redução do número de árvores para as classes de maior DAP, a exemplo do observado nas demais posições da encosta. Autores como Herwitz e Young (1994), ao estudarem a composição florística em floresta tropical na Austrália, constaram que nos divisores de drenagem o recrutamento de plântulas costuma não ser suficiente para compensar as taxas de mortalidade de jovens árvores. No caso de DV, um maior número de árvores de DAP entre $10 \mathrm{e} 20 \mathrm{~cm}$ indica um maior desenvolvimento das árvores jovens, provavelmente, pela maior chegada de luz dada a maior abertura do seu dossel (DV: $8,7 \%$; AE: 4,2\%; BE: 4,0\%; e FV 4,3\%), que dificilmente atingirão fases mais maduras de desenvolvimento.

Tabela 1: Dados de estrutura da vegetação (DAP-diâmetro à altura do peito; DV-Divisor de Drenagem; AE-Alta Encosta; BE-Baixa Encosta; FV-Fundo de Vale; e DP-desvio padrão).

\begin{tabular}{lccccccc}
\cline { 2 - 7 } & $\begin{array}{c}\text { DAP médio } \\
(\mathrm{cm})\end{array}$ & $\begin{array}{c}\text { Densidade } \\
\left(\text { ind.ha }^{-1}\right)\end{array}$ & $\begin{array}{c}\text { Área Basal } \\
\left(\mathrm{m}^{2} . \mathrm{ha}^{-1}\right)\end{array}$ & $\begin{array}{c}\text { Maior DAP } \\
(\mathrm{cm})\end{array}$ & $\begin{array}{c}\text { Altura } \\
\text { média }(\mathrm{m})\end{array}$ & $\begin{array}{c}\text { Palmeiras } \\
\left(\mathrm{n}^{\circ} \text { ind. }\right)\end{array}$ & $\begin{array}{c}\text { Árv. } \\
\text { mortas }\end{array}$ \\
\hline DV & 14,54 & 2599,97 & 70,94 & 70,7 & 8,42 & 36 & 07 \\
AE & 12,63 & 2099,98 & 42,83 & 57,32 & 8,67 & 12 & 00 \\
BE & 13,23 & 1933,31 & 48,66 & 57,96 & 9,54 & 18 & 03 \\
FV & 16,51 & 1399,99 & 52,68 & 59,84 & 8,61 & 03 & 02 \\
Média & 14,2 & 2008,3 & 53,8 & 61,5 & 8,81 & - & - \\
DP & 1,72 & 494,7 & 12,1 & 6,26 & 0,50 & - & - \\
\hline
\end{tabular}

O maior número de palmeiras foi outro destaque para o DV, área que também apresentou maior número de árvores mortas. O maior número de palmeiras no DV deve ocorrer em razão da condição de maior luminosidade, assim como observaram Kindel e Garay (2001) na Mata Atlântica de Tabuleiros (ES). Em contraste ao que acontece nas demais posições na encosta, no DV, algumas palmeiras alcançam o dossel superior, que se encontra há cerca de $15 \mathrm{~m}$ de altura nesta área, rompido por árvores emergentes de aproximadamente $20 \mathrm{~m}$ (Miranda et al., 2014). Nas áreas da AE, da BE e no FV, o dossel superior encontra-se mais alto, em cerca de 20 $\mathrm{m}$ de altura, com árvores emergentes que podem ultrapassar os $25 \mathrm{~m}$ e com as palmeiras em menor número, confinadas ao estrato inferior (Miranda et al., op cit.). 


\section{Dinâmica de Matéria Orgânica de Superfície Condicionada Pela Topografia em Floresta Atlântica}

Stefani (2017) analisou as variações na distribuição de palmeiras ao longo do gradiente altimétrico na Serra do Mar: Floresta Ombrófila Densa Submontana / Floresta Ombrófila Densa Montana. Este autor indicou a tendência das palmeiras serem mais altas na variação Submontana da Floresta Ombrófila Densa, por vezes, ocupando o dossel superior, enquanto eram mais baixas e confinadas ao estrato inferior na variação Montana. Contudo, em contraposição ao fator altimétrico (condições ambientais vinculadas à altitude), Rizzini (1997) expõe que as formações florestais mais típicas da variação Montana costumam aparecer precocemente pelos fundos de vale, onde se concentra a umidade como reflexo do contexto geomorfológico local.

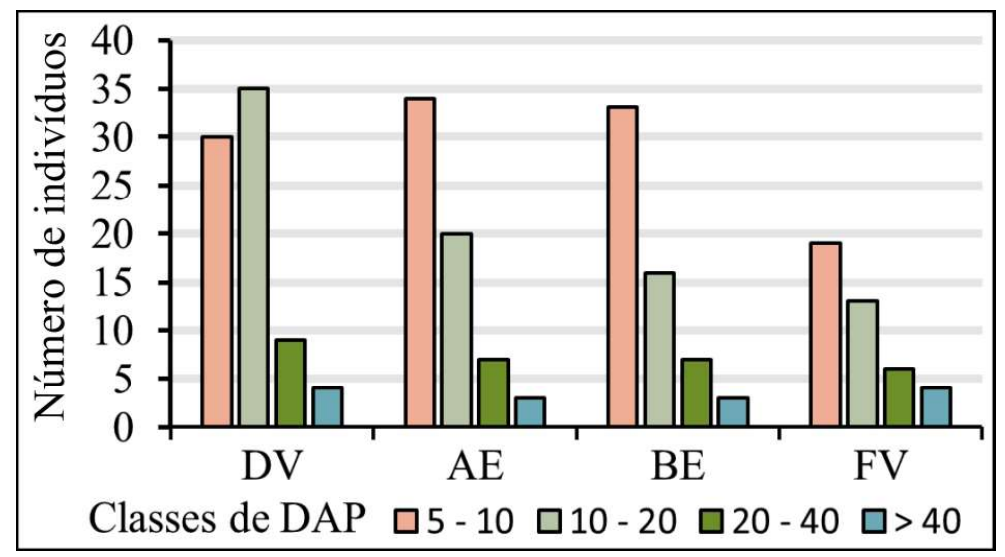

Figura 3 - Distribuição do número de indivíduos arbóreos nas classes de DAP (cm) para cada posição na encosta (DV-Divisor de Drenagem; AE-Alta Encosta; BE-Baixa Encosta; e FV-Fundo de Vale).

Frente às constatações da maior ocorrência de palmeiras no DV, onde estas alcançam o dossel superior, este, por sua vez, comparativamente mais baixo e com maior abertura, além desta posição apresentar um maior número de árvores mortas e uma maior densidade de indivíduos, infere-se que o DV exibe uma versão menos desenvolvida da vegetação, de aspecto um pouco mais seco no contexto da heterogeneidade local. Tal condição ocorre em razão do gradiente de umidade vinculado à geomorfologia local, fator este que se sobrepõe aos vinculados à altitude no contexto da baixa amplitude altimétrica da encosta $(150 \mathrm{~m})$, já que seria esperado um quadro oposto em um gradiente de variação de uma formação Submontana para uma formação Montana (árvores mais altas, com maiores DAPs e maior fechamento do dossel). Dessa forma, a presença de indivíduos de grande porte em DV (maior DAP observado), único indicador contraditório, parece um pouco descontextualizada ecologicamente, podendo ser resultado - assim como nas demais áreas - da ação direta de reflorestamento no Morro do Archer (Drummond, 1988).

$\mathrm{O}$ aporte de detritos orgânicos na encosta foi de $7,15( \pm 0,77) \mathrm{Mg}_{\mathrm{ha}} \mathrm{h}^{-1}$.ano ${ }^{-1}$, valor um pouco abaixo, porém próximo, ao obtido por Oliveira e Lacerda (1987) no mesmo fragmento florestal $\left(8,9 \mathrm{Mg} \cdot \mathrm{ha}^{-1} \cdot\right.$ ano $\left.^{-1}\right)$ e por Flor et al., (2017) em fragmento de Floresta Ombrófila Densa em Santa Catarina (8,13 Mg.ha ${ }^{-1} \cdot$ ano $\left.^{-1}\right)$. Foram observadas variações sazonais, com maiores valores de deposição no segundo semestre de 2016 (figura 4). Em janeiro e fevereiro de 2017 o aporte de detritos decaiu, apresentando valores similares aos meses do primeiro semestre de 2016. Os meses de março, abril e junho (2016) foram os que apresentaram menor queda de detritos. O mês de Junho costuma ser um dos mais secos do ano, mas, no período estudado, foi este o mês de maior precipitação acumulada.

$\mathrm{O}$ aumento na queda de detritos no segundo semestre de 2016 foi impulsionado pelo maior aporte de folhas, principalmente, no DV e na AE. As Florestas Ombrófilas Densas do sudeste brasileiro costumam apresentar baixa sazonalidade na deposição de folhas (florestas sempre verdes), pois tendem a apresentar número reduzido de espécies caducifólias (praticamente ausentes) ou semicaducifolias em matas de sucessão mais avançada (Flor, 2017). Contudo, nestas formações algumas plantas podem apresentar queda mais acentuada de folhas em condições de estresse hídrico (Golley, 1983). A deposição de detritos apresentou uma correlação linear mais forte à precipitação do mês anterior $(\mathrm{R}=$ 
-0,71) em comparação ao calculado para a precipitação do próprio mês em questão $(\mathrm{R}=-0,03)$. É possível inferir que as áreas na porção superior da encosta (DV e AE), as quais apresentaram maior aumento sazonal no aporte de folhas, possam ser mais susceptíveis a condição de estresse hídrico no caso de estiagens.

Todas as posições na encosta apresentaram proporção de folhas próxima a 70\% no material aportado, valor este indicado por Golley (1983) como a proporção típica das florestas tropicais. A maior presença proporcional de MR $(13,2 \%)$ deve explicar a menor proporção de folhas observada no DV $(67,2 \%)$, uma vez que o aporte de folhas, em massa, nesta posição da encosta, foi próximo ao observado nas demais áreas. A maior proporção de folhas no material aportado foi observada no FV (80,3\%), posição que apresentou a menor proporção de ML (14,9\%) em comparação ao DV $(19,7 \%)$, à $\mathrm{AE}(18,1 \%)$ e à $\mathrm{BE}(17,3 \%)$. Fora do DV, o MR apresentou patamares similares, a saber: $4,3 \%$ na AE; $6,6 \%$ na BE; e $4,8 \%$ no FV.

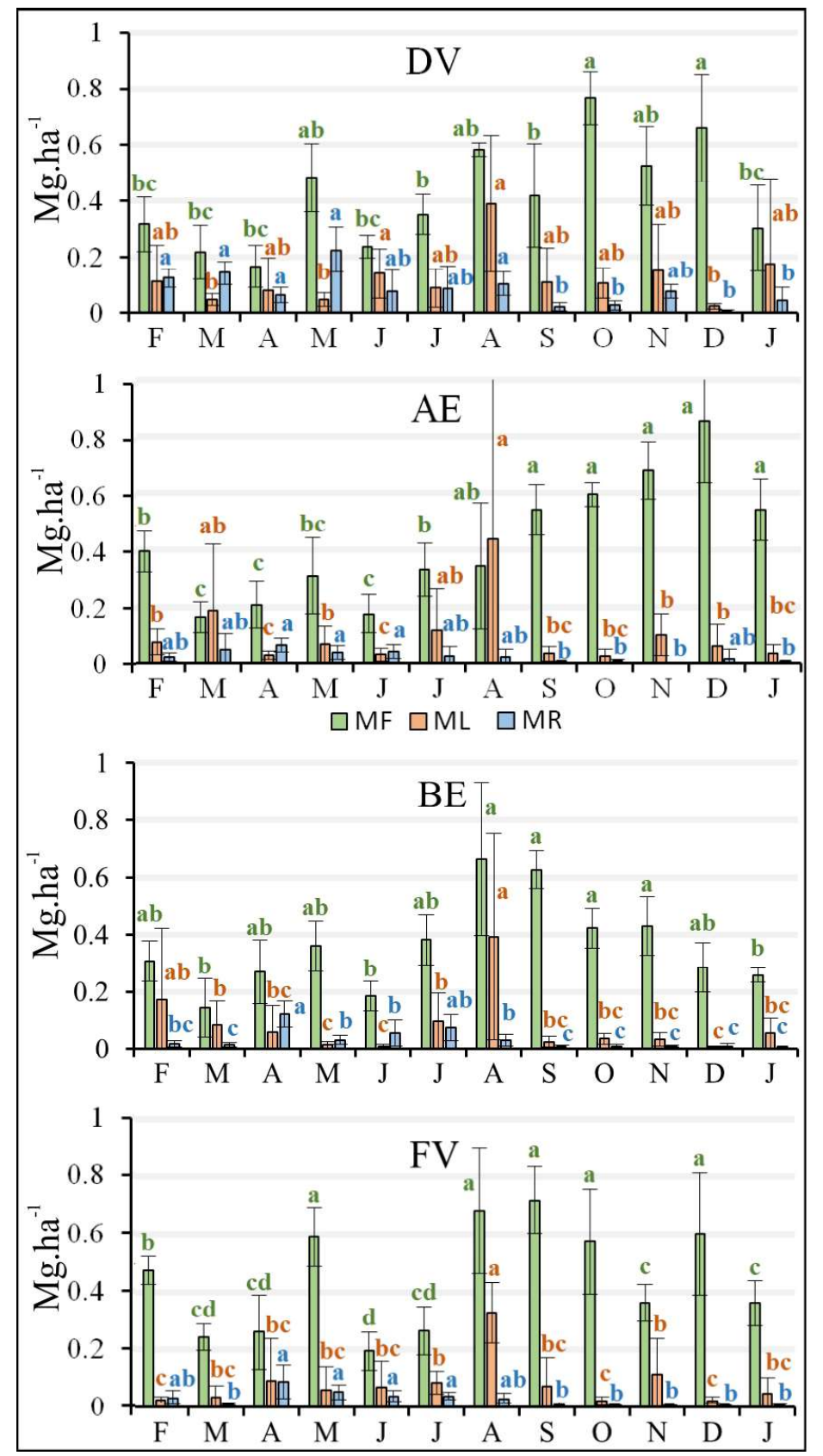

Figura 4 - Aporte mensal de detritos dos diferentes tecidos ao solo em cada área (DV-Divisor de Drenagem; AE-Alta Encosta; BE-Baixa Encosta; e FV-Fundo de Vale) ao longo de um ano. As letras minúsculas indicam as populações de dados significativamente variantes variação entre os meses do ano para cada tipo de tecido pelo teste Dunn. 


\section{Dinâmica de Matéria Orgânica de Superfície Condicionada Pela Topografia em Floresta Atlântica}

Embora tenham sido observadas diferenças no aporte de MF (menor na BE) e de MR (maior no DV) (figura 5a), quando considerada a massa aportada independente o tipo de tecido, a queda anual de detritos lenhosos não variou significativamente entre as posições na encosta (figura 5b). Deste modo, temos que a heterogeneidade encontrada na estrutura da vegetação ao longo da encosta, pode influenciar, em parte, a dinâmica sazonal de queda de detritos ou gerar diferenças em relação à proporcão dos diferentes tipos de tecidos aportados. Contudo, não se materializou em diferenças no total de massa orgânica aportada entre as diferentes posições na encosta.

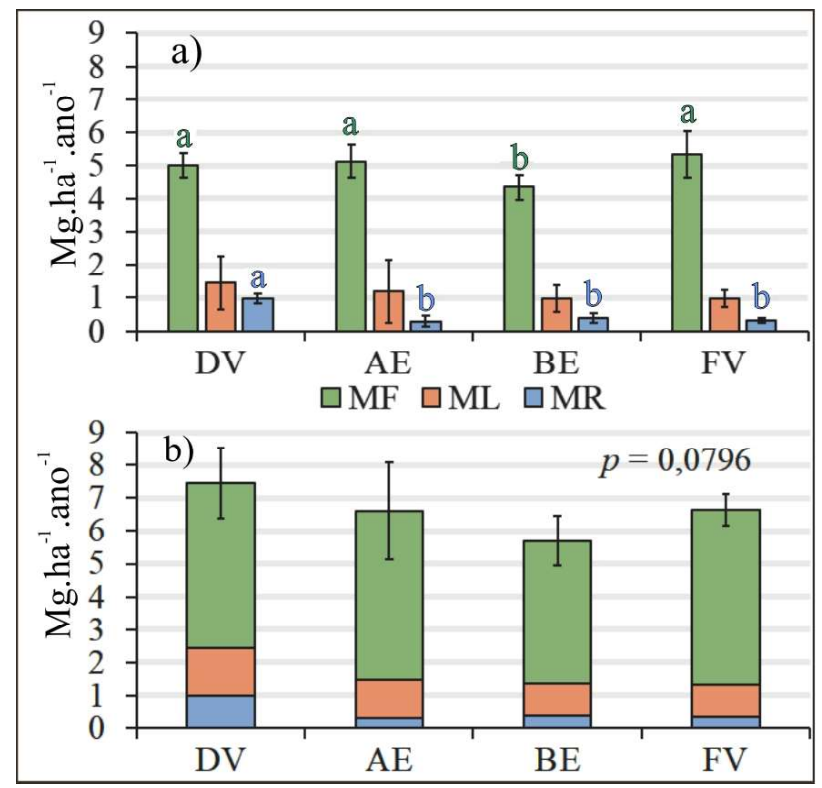

Figura 5 - Queda dos diferentes tipos de materiais orgânicos (foliar - MF; lenhoso - ML; e reprodutivo - MR) e totais de detritos aportados em cada área nas diferentes posições na encosta (DV-Divisor de Drenagem; AE-Alta Encosta; BE-Baixa Encosta; e FV-Fundo de Vale). Valor p para o teste $K$-W para os totais aportados (b).

\subsection{Redistribuição espacial de serapilheira}

Acerca do deslocamento lateral de serapilheira, um total de 109,21 $( \pm 37,7)$ g.m ${ }^{-1}$ de material foi capturado nas áreas íngremes, enquanto apenas 8,37 $( \pm 2,1)$ g. $\mathrm{m}^{-1}$ foi capturado nas áreas planas, após 16 semanas de monitoramento. Dentre as subáreas íngremes, o deslocamento foi maior em ME-I (figura 6a), resultado provavelmente vinculado à existência de uma maior área contínua com declividade acentuada a montantee adjacente - da subárea ME-I. Não foi significativa a variação entre as subáreas planas.

A considerável diferença entre os valores encontrados nas situações plana $\left(0-10^{\circ}\right)$ e íngreme $\left(30-40^{\circ}\right)$, exposta na figura $6 \mathrm{~b}$, indica que a declividade local pode influenciar o deslocamento lateral de detritos orgânicos, no caso, com movimento no sentido encosta abaixo. Com isto, a necromassa aportada pode não se depositar abaixo da área de abrangência do dossel de origem, podendo ser redistribuída no sentido encosta abaixo nos terrenos mais íngremes.
O deslocamento lateral nas áreas íngremes apresentou forte correlação temporal com a deposição de detritos, a qual foi maior do que em relação à chuva (figura 7). Este resultado indica que a maior parte da redistribuição ocorre no momento da queda dos detritos, sem a necessidade da ocorrência de chuva para um transporte de superfície pela água.

Ou seja, no momento da queda do material, locais mais íngremes podem apresentar dificuldade de retê-lo, de forma que os detritos podem seguir em caminho encosta abaixo até encontrar uma área menos íngreme ou algum obstáculo como blocos de rocha ou raízes. A afinidade moderada observada em relação à chuva deve ser indireta ou residual, vinculada à influência de condições atmosféricas tempestuosas para a queda das folhas senis.

A maior presença de material reprodutivo no deslocamento lateral em relação ao observado na queda de detritos no mesmo período indica o favorecimento das sementes à redistribuição, provavelmente, pela forma esférica de muitas (tabela 2). O material lenhoso apresentou a menor tendência à redistribuição. 


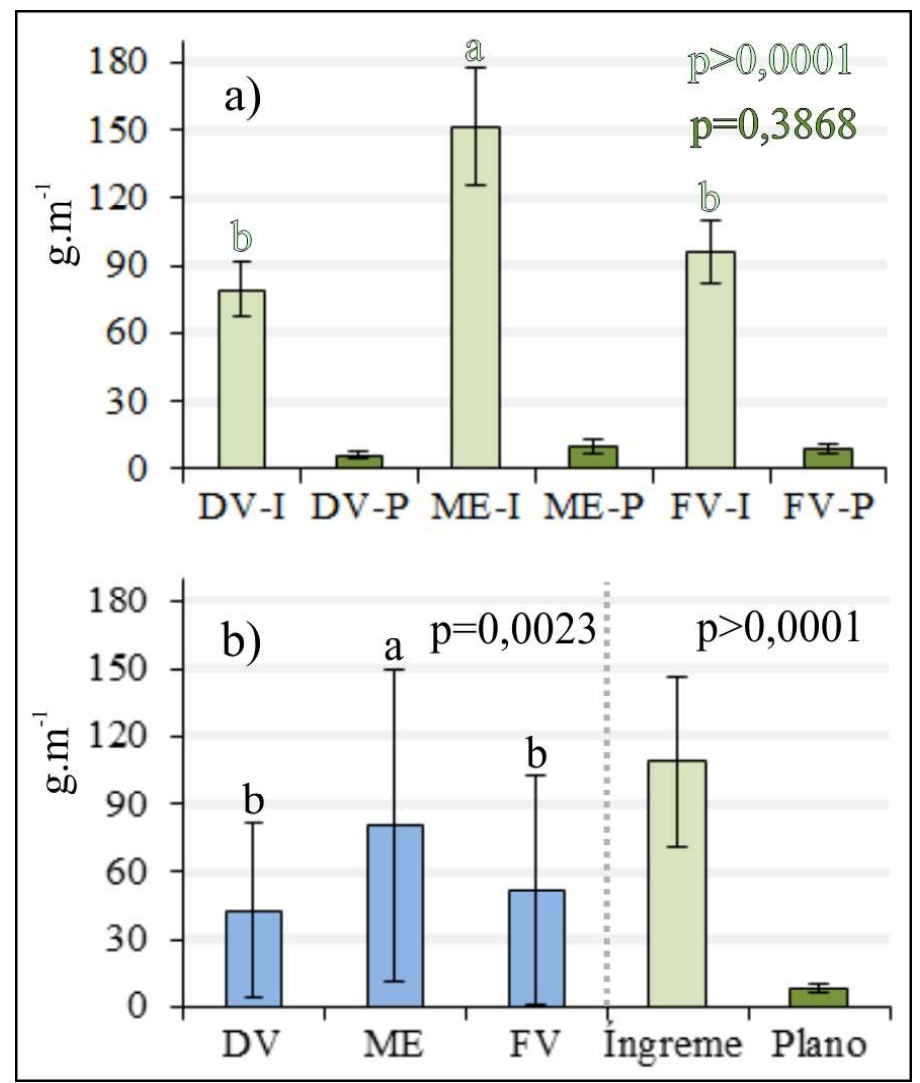

Figura 6 - Deslocamento lateral de serapilheira em cada subárea (I-íngreme; e P-plano) em três posições na encosta (DV-Divisor; MEMédia Encosta; e FV-Fundo de Vale) (a). Valores médios para cada posição na encosta (média entre as subáreas íngreme e plana) e cada condição de declividade (média entre as três posições na encosta) (b).

Ao longo do experimento com folhas marcadas, apenas uma destas folhas foi capturada nos coletores de deslocamento lateral, fato verificado em ME-I, com área de origem da folha há $01 \mathrm{~m}$ do coletor, ocorrido na $4^{\mathrm{a}}$ semana de experimento. Após a $4^{\mathrm{a}}$ semana o experimento chegou ao fim, uma vez que não era mais possível encontrar as folhas marcadas onde estas haviam sido inicialmente colocadas. Todas as folhas "sumiram" na mesma semana (4a semana), semana esta (03-10/06/2013) que apresentou a maior pluviosidade acumulada $(228 \mathrm{~mm})$ dentre as 16 semanas de monitoramento da $1^{\mathrm{a}}$ etapa de pesquisa.

Diversos pequenos fragmentos de folhas marcadas foram avistados a jusante das áreas dos coletores nas semanas seguintes, às vezes, há mais de 20 metros de distância da área de origem mais próxima. A área do fundo de vale começou a apresentar grande número destes pequenos fragmentos após cerca de 06 semanas do início do experimento (figura 8).
O "desaparecimento" das folhas na $4^{\mathrm{a}}$ semana de experimento e a posterior "chegada" de fragmentos no fundo de vale nas semanas seguintes indicam que tanto folhas íntegras, quanto fragmentos de diferentes tamanhos, já depositados sobre o solo, podem também deslocarem-se no sentido encosta abaixo. Neste caso, é provável a ação transportadora da água em eventos de chuva. No caso dos pequenos fragmentos, é provável que possam se deslocar mesmo quando não há a formação de escoamentos superficiais na encosta, pela ação dos fluxos intraserrapilheira descritos por Coelho Netto (1987), também na Floresta da Tijuca. Contudo, uma discussão acerca das circunstâncias, dos mecanismos e das taxas destes movimentos necessitariam de uma investigação própria. Por hora, indica-se apenas que o movimento pode ocorrer - confirmado pelo experimento - mesmo em um ambiente onde a formação de escoamentos superficiais é incomum (Fernandes et al., 2006) e fora dos eixos de concavidade da encosta onde estes se formariam primeiro. 


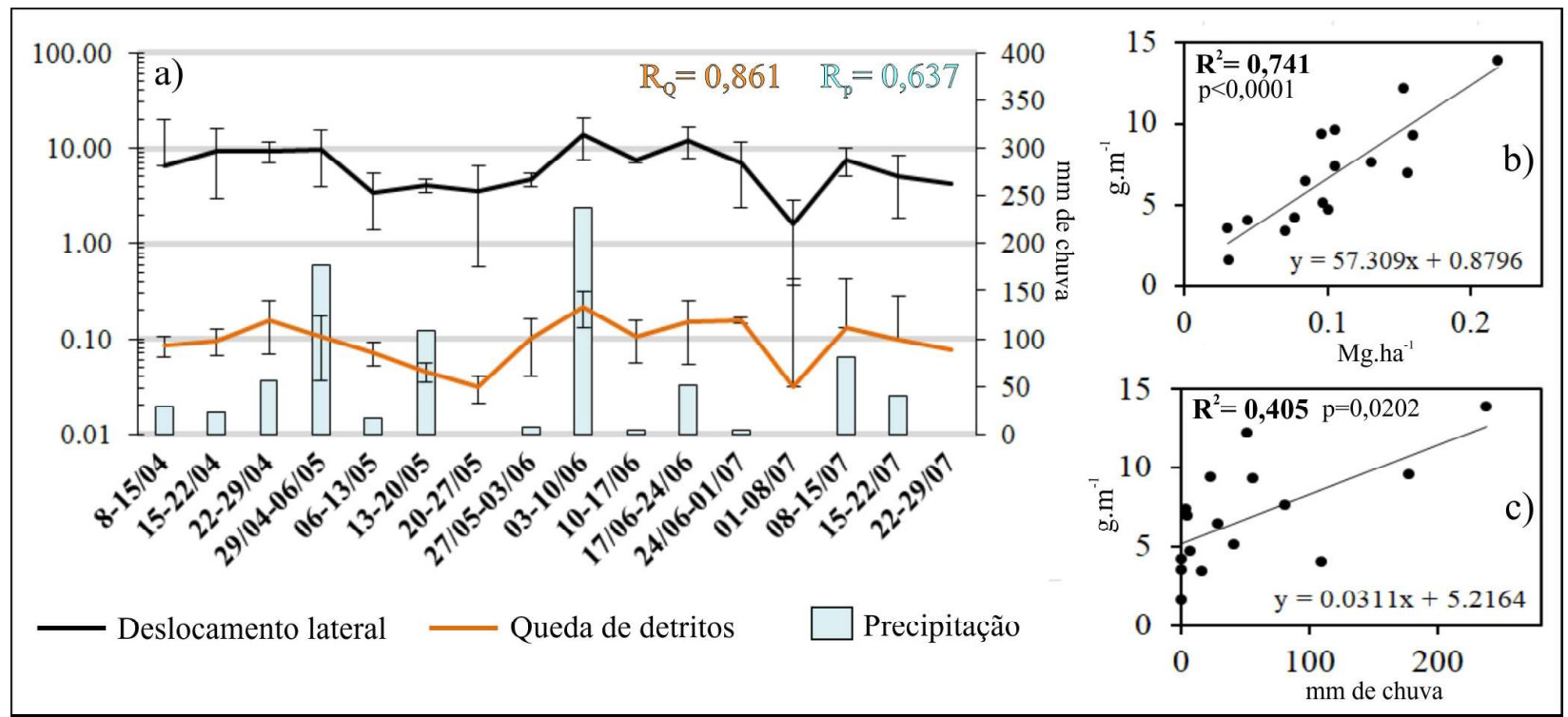

Figura 7 - Correspondência temporal do deslocamento lateral de serapilheira (g.m $\left.m^{-1}\right)$ em relação à queda de detritos $\left(M g . h a^{-1}\right)$ e aos acumulados semanais de chuva ( $\mathrm{mm}$ ), com os valores de correlação linear de Pearson dos dados de deslocamento lateral em relação à queda de detritos $\left(R_{Q}\right)$ e à precipitação semanal $\left(R_{p}\right)(a)$. Dispersão dos dados de deslocamento lateral em relação à queda de detritos (b) e à precipitação (c), com suas respectivas retas de regressão linear, coeficientes de determinação $\left(\mathbf{R}^{2}\right)$ e valor p de significância do modelo linear.

Tabela 2: Percentuais da contribuição dos diferentes tecidos na queda de detritos $\left(1^{\mathrm{a}}\right.$ etapa, subitem 2.4) e deslocamento lateral da serapilheira, nas diferentes subáreas (I-íngreme; e P-plano) em três posições da encosta (DV-Divisor de drenagem; ME-Média Encosta; e FV-Fundo de Vale).

\begin{tabular}{ccccccc}
\hline \multirow{2}{*}{$(\%)$} & \multicolumn{2}{c}{ Folhas } & \multicolumn{2}{c}{ Lenhosos } & \multicolumn{2}{c}{ Reprodutivos } \\
\cline { 2 - 7 } & Queda & Desloc. Lat. & Queda & Desloc. Lat. & Queda & Desloc. Lat. \\
\hline DV-P & 47.31 & $\mathbf{7 0 . 3 7}$ & 38.07 & $\mathbf{2 6 . 9 6}$ & 5.69 & $\mathbf{2 . 6 7}$ \\
DV-I & 76.31 & $\mathbf{6 6 . 6 1}$ & 20.40 & $\mathbf{2 3 . 6 1}$ & 3.29 & $\mathbf{9 . 7 8}$ \\
ME-P & 60.94 & $\mathbf{7 0 . 4 0}$ & 18.45 & $\mathbf{1 7 . 8 7}$ & 10.46 & $\mathbf{1 1 . 7 3}$ \\
ME-I & 69.66 & $\mathbf{7 4 . 5 0}$ & 13.42 & $\mathbf{1 1 . 6 4}$ & 9.33 & $\mathbf{1 3 . 8 6}$ \\
FV-P & 58.81 & $\mathbf{6 7 . 9 1}$ & 17.22 & $\mathbf{1 3 . 0 6}$ & 15.36 & $\mathbf{1 9 . 0 2}$ \\
FV-I & 76.71 & $\mathbf{6 5 . 5 1}$ & 13.32 & $\mathbf{1 6 . 1 9}$ & 7.50 & $\mathbf{1 8 . 3 0}$ \\
\hline
\end{tabular}

A redistribuição espacial de serapilheira já foi estudada em ambientes glaciais e temperados, associada aos fluxos de derretimento de neve (Orndoff e Lang, 1981; Fahnestock et al., 2000) e a fluxos superficiais de chuvas (Gurtz et al., 1988; Yan et al., 2016). Nas encostas de florestas tropicais não parece comum observações do tipo, uma vez que são ambientes teoricamente pouco afetados por tais fatores.

No Brasil, Tonin et al. (2017) realizaram um amplo estudo sobre a entrada lateral de serapilheira em riachos, reflexo do movimento lateral na zona ripária, a qual ocorre por uma combinação dos seguintes fatores: a queda de detritos, a precipitação e o vento nos ambientes de Cerrado; a queda de detritos e a precipitação para a Amazônia; e a declividade para a Mata Atlântica. Folhas secas são mais facilmente transportadas e a associação de ambiente seco (folhas secas) e aberto (suscetibilidade aos agentes) coloca o Cerrado como o ambiente de maior mobilidade lateral de folhas em direção aos riachos, enquanto a Mata Atlântica se destaca como o ambiente onde há menor ocorrência.

Neste contexto, uma grande quantidade de blocos de rocha nas encostas, assim como grandes raízes com sapopemas, atuam como obstáculos ao deslocamento lateral de detritos e promovem certa proteção à chegada das folhas aos riachos da Mata Atlântica. O movimento 
lateral observado neste trabalho parece influenciar mais a heterogeneidade da espessura dos estoques ao longo da encosta, sob a influência das feições microtopográficas, onde pode haver dificuldade de retenção de detritos nas áreas desobstruídas e acúmulo de material em maior quantidade acima de raízes e blocos de rocha.

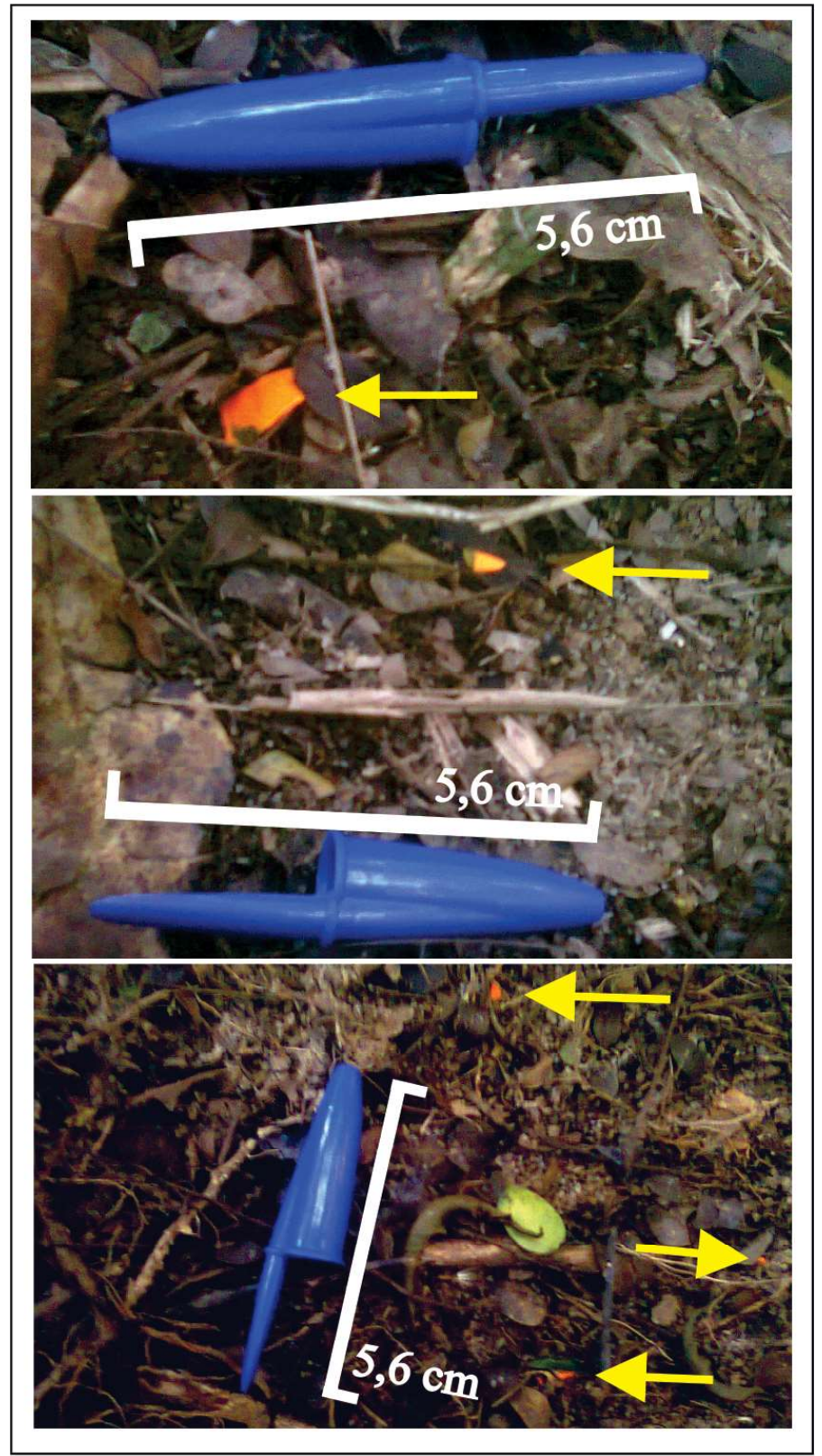

Figura 8 - Exemplos dos pequenos fragmentos de folhas marcadas identificados no estoque de serapilheira próximo ao fundo de vale, 09 semanas após o início do experimento.

\subsection{Acumulação de serapilheira ao longo da encosta}

\subsubsection{Sazonalidade}

O estoque de serapilheira na encosta foi estimado $8,92 \mathrm{Mg} \mathrm{ha}^{-1}( \pm 2,78)$ ao fim do inverno (2016) e 6,71

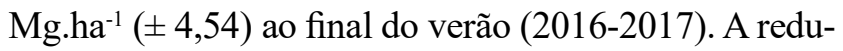
ção do estoque do inverno para o verão é resultado do favorecimento da atuação bioquímica sobre o material - aumento da taxa de decomposição - em condições de maiores temperaturas e umidade, típicas do verão da região. Resultado similar foi reportado por Borém e Ramos (2002) em ambiente de Mata Atlântica da região serrana do RJ, observada a redução do estoque de serapilheira ao fim da estação chuvosa em comparação à estação seca. 


\section{Dinâmica de Matéria Orgânica de Superfície Condicionada Pela Topografia em Floresta Atlântica}

O efeito da sazonalidade sobre as taxas de decomposição sobressaiu à tendência de aumento de aporte de detritos na encosta no $2^{\circ}$ semestre de 2016 , apresentando menor estoque no verão mesmo sob esta condição. Tal tendência é indicada pela redução da acumulação de FF. Autores como Kindel e Garay (2001), assim como Werner e Homeyer (2015), ressaltam que uma maior acumulação de material já fragmentado é típico de estoques de serapilheira com menores taxas de decomposição.

A sazonalidade afetou de forma diferenciada os estoques de serapilheira nas diferentes posições na encosta (figura 9). A camada de FL variou na BE, apresentando maior acúmulo no verão como reflexo do aumento da queda de folhas no $2^{\circ}$ semestre de 2016. Não foram significativas as diferenças nas outras áreas para este constituinte da serapilheira. A variação sazonal da camada de FF se concentrou nas áreas do DV e da BE. Nas demais áreas não foi significativa a variação desta camada constituinte. Os materiais lenhosos e reprodutivos (ML e MR) não variaram significativamente entre as estações em nenhuma das posições na encosta.

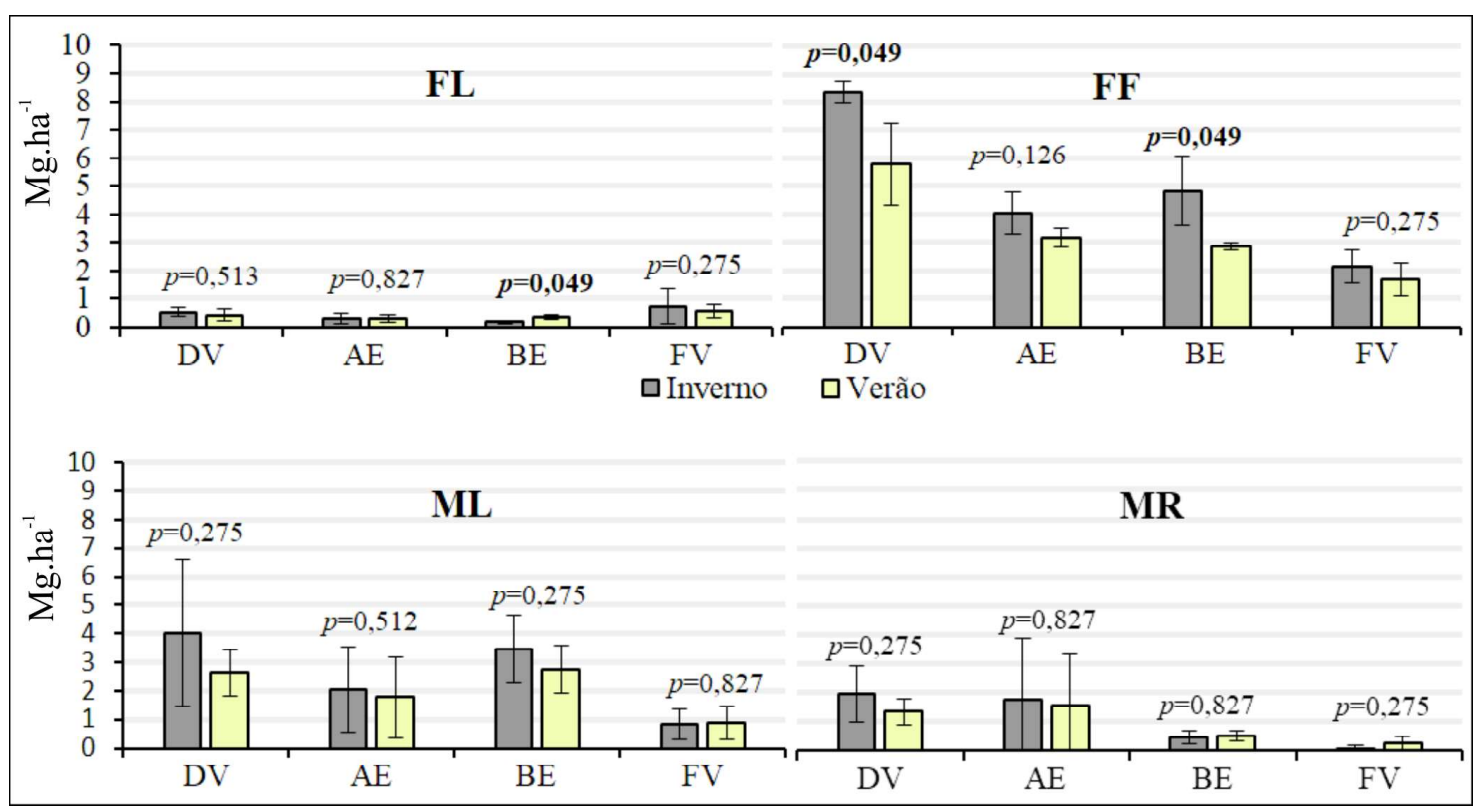

Figura 9 - Variação sazonal dos diferentes componentes estruturais dos estoques de serapilheira nas diferentes posições na encosta (DV-Divisor de Drenagem; AE-Alta Encosta; BE-Baixa Encosta; e FV-Fundo de Vale) e valor p do teste ANOVA sobre o efeito do Período (tratamento).

\subsubsection{Estoque anual de serapilheira}

Em termos médios ao observado no final do inverno e final do verão, o estoque de serapilheira na encosta foi estimado em 7,72 Mg.ha ${ }^{-1}( \pm 3,68)$. Autores como Borém e Ramos (2002) encontraram cerca de 7,06 Mg.ha' ${ }^{-1} \mathrm{em}$ fragmento florestal pouco impactado na região serrana do RJ, e uma estocagem um pouco maior (8,47 Mg.ha $\left.{ }^{-1}\right)$ em área com sucessão florestal menos desenvolvida, sob condições ambientais similares. Neste contexto, os valores observados no presente trabalho representam um patamar mediano aos encontrados por tais autores, porém, aqui foi observado o efeito da posição na encosta sobre a estocagem de serapilheira, a qual foi testada e refutada (estatisticamente não significativa) para a área de estudo dos citados autores.
Os estoques de serapilheira apresentaram-se espacialmente heterogêneo em termos de massa e estrutura em relação às diferentes posições na encosta. Foi observado um grande acúmulo de FF no DV, enquanto as áreas de encosta (AE e BE) apresentaram valores mais baixos e próximos entre si, e o FV apresentou a menor acumulação deste constituinte (figura 10a). As folhas novas (FL) não variaram em acumulação entre as posições na encosta. O acumulo de ML foi menor no FV. $\mathrm{O}$ constituinte MR foi mais presente nas duas posições superiores na encosta. Considerando-se que este tipo de material apresentou maior massa aportada somente no $\mathrm{DV}$, é provável que a área da $\mathrm{AE}$ receba, com alguma frequência, sementes originadas da área a montante, depositadas na $\mathrm{AE}$ por meio do deslocamento lateral. 
Em termos percentuais, os tecidos foliares (FL + FF) representaram $57,9 \%$ da massa estocada na encosta, variando espacialmente entre 70,9\% (FV) e 52,0\% (AE). Os ML representaram 29,4\% variando entre 40,2\% (BE) e 24,1\% (FV). Os MR representaram 12,7\% na encosta, variando entre $22,3 \%$ (AE) e 4,9\% (FV). As diferenças mais contundentes entre as áreas são o grande acúmulo de FF em DV, o maior acúmulo de lenho em BE, e o maior acúmulo de MR em ambas as áreas de montante (DV e AE). O aumento na proporção de ML no estoque sobre o solo em relação ao observado na queda de detritos é esperada, uma vez que este tipo de material é mais resistente à decomposição. Em contraste, as folhas são mais susceptíveis a degradação bioquímica e, por esta razão, tendem a reduzir sua proporção no estoque em comparação ao observado no aporte. Golley (1983) ressalta que as folhas são componentes importantes da ciclagem rápida de nutrientes em florestas tropicais, mas que a maior parte dos nutrientes estão estocados nos materiais lenhosos em ciclagem lenta.

Considerando-se todos os constituintes, foi observado um maior acúmulo de serapilheira no DV e menor no FV (figura 10b). As áreas de meia encosta, $\mathrm{AE}$ e $\mathrm{BE}$, apresentaram valores intermediários e não diferiram estatisticamente (a posteriori) do DV ou do FV (figura 9b). Resultado semelhante foi encontrado em Floresta Ombrófila Montana na Serra do Mar por Saraiva et al., (2016), porém, aqui, as diferenças nos estoques vinculadas à topografia se demonstraram mais expressivas, observado um acumulo de detritos no DV 03 vezes superior do que no FV. Levando-se em conta que a massa de detritos aportados foi similar entre as áreas, a diferença de massa de serapilheira estocada está associada a taxas de decomposição diferenciadas, demonstrado pelo índice de decomposição k' que foi maior para o $\mathrm{FV}\left(\mathrm{K}^{\prime}=2,03\right)$ e intermediários na $\mathrm{BE}$ $\left(K^{\prime}=0,80\right)$ e na $A E\left(K^{\prime}=0,96\right)$. $A$ área do $D V$, com maior estoque acumulado, apresentou o menor índice $\left(\mathrm{K}^{\prime}=0,62\right)$.

Em condição de encosta, um favorecimento à maior concentração de umidade no sentido encosta abaixo é esperado pela ação gravitacional sobre os fluxos hídricos. No presente estudo, confirmou-se a relevância do gradiente geomorfológico em relação ao conteúdo de umidade na serapilheira, que demonstrou tendência de aumento no sentido encosta abaixo ( $\mathrm{DV}<\mathrm{ME}<\mathrm{FV})$. A umidade contida na serapilheira, em termos percentuais frente ao seu peso seco, foi de $62,4 \%( \pm 40,4)$ no
DV; $75,6 \%( \pm 39,8)$ na ME; e $105,6 \%( \pm 36,07)$ no FV. Considerando a área do FV como referencial, a umidade foi $28,4 \%$ menor na serapilheira da ME e $41,0 \%$ menor na do DV.

O gradiente de umidade associado ao relevo deve ser o principal responsável pelas diferenças nas taxas de decomposição encontradas ao longo da encosta, considerando-se que a disponibilidade de umidade afeta positivamente a atividade bioquímica sobre a serapilheira, principalmente em ambientes onde a biodegradação é controlada por fungos, como nas Florestas Tropicais (Swift et al., 1979; Tonhasca-Júnior, 2005). Autores como Kindel e Garay (2001) e Werner e Homeyer (2015) ressaltam alguns indicadores, aqui reunidos no DV, que refletem taxas de decomposição mais lentas, como pH mais ácido (tabela 3) e maior acúmulo de materiais fragmentados (FF).

Além da condição microambiental vinculada à disponibilidade de umidade, a qualidade química do material é outro fator de controle às taxas de decomposição da serapilheira (Swift et al., 1979). Levando-se em conta que, no contexto de florestas tropicais, as folhas de palmeiras costumam estar entre as mais recalcitrantes (Violita et al., 2015; Chellaiah e Yule, 2018), a maior presença de indivíduos desta família é mais um condicionante à decomposição mais lenta da serapilheira no DV. Foi observada similaridade inversa e não linear entre o número de indivíduos de palmeiras e o índice de decomposição K' nas 04 posições na encosta analisadas (figura 11). Contudo, sem um estudo com desenho específico para o tema é difícil avaliar as relações de causalidade na correlação observada entre a massa de serapilheira acumulada e a ocorrência de palmeiras na área estudada, uma vez que espessos estoques podem favorecer a ocorrência desta família (Marcos e Matos, 2003), assim como tal ocorrência pode favorecer espessos estoques pela maior resistência à decomposição das suas folhas.

Ambas as áreas de encosta (AE e BE) encontram-se em contexto mais íngreme e apresentaram maior variabilidade interna na massa estocada, evidenciada pelos maiores valores de Desvio Padrão. Tal observação corrobora a ideia de deslocamento lateral e reforça a interpretação de que este movimento promova uma acumulação espacialmente mais heterogênea em áreas de declive acentuado, com maior acúmulo de material acima de obstáculos ao movimento encosta abaixo. 


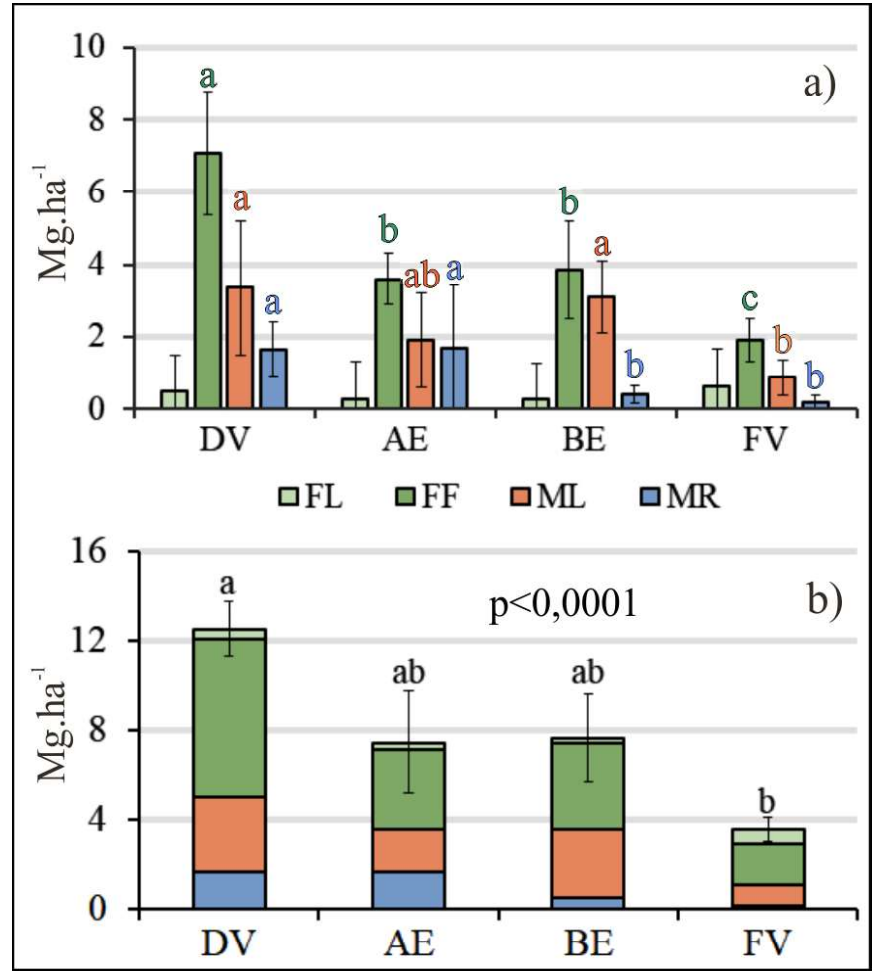

Figura 10 - Acúmulo dos diferentes componentes estruturais da necromassa sobre o solo (a) e estoque total de serapilheira nas diferentes posições na encosta (DV-Divisor de Drenagem; AE-Alta Encosta; BE-Baixa Encosta; e FV-Fundo de Vale) (b). Valor p do teste ANOVA para o efeito das áreas (blocos) sobre o estoque total de serapilheira. As letras minúsculas indicam as populações estatísticas entre as áreas pelo teste Dunn.

Tabela 3: Atributos químicos do solo nas diferentes posições na encosta (DV-Divisor de Drenagem; ME-Média Encosta; e FV-Fundo de Vale) e valor do teste K-W (p) para as áreas, em negrito quando significativo (p<0,05). As letras minúsculas em negrito indicam populações estatisticamente similares ou variantes pelo teste Dunn a posteriori.

\begin{tabular}{ccccccc}
\hline & \multicolumn{7}{c}{$\mathrm{cmol}^{-\mathrm{dm}^{-3}}$} \\
\cline { 2 - 6 } & $\mathrm{Al}$ & $\mathrm{Ca}$ & $\mathrm{Mg}$ & $\mathrm{Na}$ & $\mathrm{K}$ & $\mathrm{P}$ \\
\hline $\mathrm{DV}$ & $1,5 \pm 0,4 \mathbf{a}$ & $1,4 \pm 0,2 \mathbf{b}$ & $1,4 \pm 0,3$ & $0,09 \pm 0,1 \mathbf{a}$ & $0,09 \pm 0,01 \mathbf{b}$ & $4,3\left(10^{-3}\right) \pm 3,6\left(10^{-4}\right) \mathbf{b}$ \\
$\mathrm{ME}$ & $0,65 \pm 0,2 \mathbf{a b}$ & $1,7 \pm 0,2 \mathbf{a}$ & $1,5 \pm 0,1$ & $0 \mathbf{b}$ & $0,17 \pm 0,07 \mathbf{a b}$ & $7,6\left(10^{-3}\right) \pm 3,6\left(10^{-3}\right) \mathbf{a}$ \\
$\mathrm{FV}$ & $0,45 \pm 0,1 \mathbf{b}$ & $1,7 \pm 0,1 \mathbf{a}$ & $1,35 \pm 0,2$ & $0,04 \pm 0,01 \mathbf{a b}$ & $0,19 \pm 0,04 \mathbf{a}$ & $4,5\left(10^{-3}\right) \pm 1,2\left(10^{-4}\right) \mathbf{a b}$ \\
$\boldsymbol{p}$ & $\mathbf{0 , 0 0 7 9}$ & $\mathbf{0 , 0 2 6 8}$ & 0,195 & $\mathbf{0 , 0 1 6 2}$ & $\mathbf{0 , 0 2 0 9}$ & $\mathbf{0 , 0 0 8 7}$ \\
\hline & \multicolumn{7}{c}{$\mathrm{cmolc.dm}^{-3}$} & & $\%$ & $\mathrm{~g}^{-1} \mathrm{~kg}^{-1}$ & \\
& $\mathrm{Al}+\mathrm{H}$ & $\mathrm{S}$ & $\mathrm{T}$ & $\mathrm{V}$ & $\mathrm{C}$ org. & $\mathrm{pH}\left(\mathrm{H}_{2} \mathrm{O}\right)$ \\
\hline $\mathrm{DV}$ & $11,4 \pm 3,3 \mathbf{a}$ & $2,9 \pm 0,7$ & $14,4 \pm 2,5 \mathbf{a}$ & $21,5 \pm 9,1 \mathbf{b}$ & $33,1 \pm 16,1 \mathbf{a}$ & $4,2 \pm 0,1 \mathbf{b}$ \\
$\mathrm{ME}$ & $7,25 \pm 0,5 \mathbf{b}$ & $3,3 \pm 0,3$ & $10,6 \pm 0,2 \mathbf{a b}$ & $31,5 \pm 3,5 \mathbf{a}$ & $23,15 \pm 0,5 \mathbf{b}$ & $4,7 \pm 0,1 \mathbf{a b}$ \\
$\mathrm{FV}$ & $7,25 \pm 0,5 \mathbf{b}$ & $3,2 \pm 0,2$ & $10,5 \pm 0,7 \mathbf{b}$ & $31,0 \pm 0,7 \mathbf{a}$ & $28,3 \pm 7,6 \mathbf{a b}$ & $4,8 \mathbf{a}$ \\
$\boldsymbol{p}$ & $\mathbf{0 , 0 2 0 9}$ & 0,2986 & $\mathbf{0 , 0 2 2 2}$ & $\mathbf{0 , 0 1 5 4}$ & $\mathbf{0 , 0 4 2 1}$ & $\mathbf{0 , 0 2 4 1}$ \\
\hline
\end{tabular}


A maior acidez do solo no DV é um provável resultado do maior acúmulo de ácidos húmicos e fúlvicos, reflexo da decomposição menos eficiente nesta posição da encosta, e tal condição acarreta em mais Al disponível (Werner e Homeyer, 2015; Rodrigues et al., 2016). Nesta área (DV), a capacidade de troca catiônica total ( $\mathrm{T}$ ) foi a maior dentre as áreas, porém, a saturação por bases (V) é menor, o que deve ocorrer por conta da grande presença de $\mathrm{Al} \mathrm{e} \mathrm{H}$ interagindo com as cargas negativas do solo, similar ao observado em Guimarães et al., (2018) para um gradiente ambiental de Campinarana. Autores como Werner e Homeyer, (op cit.) apontaram que a acidez do atua solo como um importante fator limitante ao estabelecimento de espécies climácicas em Floresta Ombrófila. Contudo, Saraiva et al. (2016) concluíram que espécies de palmeiras, incluindo a Euterpe Eudilis, apresentam alta resistência às condições acidez e baixa fertilidade, o que ajuda a explicar, em parte, a sua maior presença no divisor.

Os valores de $P$ parecem não seguir o padrão sugerido por Capoane et al. (2016), o qual encontrou maiores valores em áreas planas ou baixas. Neste trabalho, os valores de $\mathrm{P}$ encontrados foram consideravelmente mais baixos do que os reportados por tais autores e maiores na área de meia encosta. A fertilidade do solo variou pouco entre a meia encosta e o fundo de vale, e toda a encosta apresenta solo distrófico ( $\mathrm{V}<50 \%$ - EMBRAPA, 2010) e ácido. Porém, nestas porções inferiores da encosta estudada (ME e FV) esta condição é um pouco mais amena pela intensificação da ciclagem de nutrientes, favorecida por uma decomposição mais eficiente da MO. O diferencial em termos de fertilidade ficou para o divisor de drenagem, que apresentou condição de solo mais ácido e de fertilidade mais baixa como provável reflexo da menor eficiência de decomposição e a maior acumulação de substâncias húmicas.

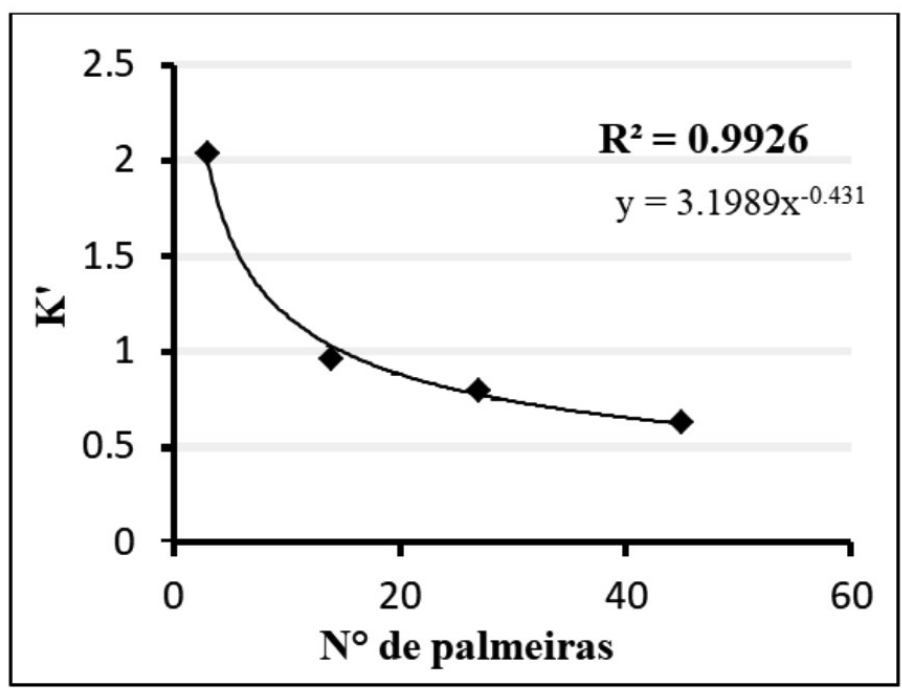

Figura 11 - Análise de dependência das taxas de decomposição $\left(K^{\prime}\right)$ em relação ao número de palmeiras em cada posição na encosta (DVDivisor de Drenagem; AE-Alta Encosta; BE-Baixa Encosta; e FV-Fundo de Vale).

\section{Conclusões}

A vegetação apresenta, em sua estrutura, alguma variação espacial vinculada ao gradiente topográfico. Os principais elementos variantes foram a redução da densidade de indivíduos no sentido encosta abaixo e a maior presença de árvores mortas e palmeiras no Divisor de Drenagem, assim como uma vegetação mais baixa e com dossel mais aberto nesta posição da encosta. Este quadro indica o gradiente de umidade vinculado à geomorfologia local como principal fator condicionante, de forma que Divisor de Drenagem exibe um ambiente florestal mais seco e luminoso em relação às demais posições na encosta.

A variação espacial encontrada na estrutura da vegetação não se manifestou em diferença significativa no aporte anual de detritos orgânicos ao solo entre as diferentes posições na encosta. Contudo, a porção superior da encosta tendeu a uma variação sazonal mais acentuada referente ao aumento na queda de folhas ao fim da estação seca, indicando maior suscetibilidade ao estresse hídrico. O material recém-aportado pode ser 
espacialmente redistribuído pelo movimento encosta abaixo - no ato da queda - nas áreas mais íngremes sem a necessidade da ação transportadora da água, enquanto folhas - ou fragmentos de folhas - já estabilizadas sobre o solo podem ser deslocadas no sentido encosta abaixo sobre a possível influencia de fluxos superficiais de água.

A crescente disponibilidade de umidade na serapilheira observada no sentido encosta abaixo controla a eficiência da decomposição na encosta. A área do Divisor de Drenagem se destaca como posição variante, exibindo espesso estoque de serapilheira como reflexo de um ambiente menos favorável a atividade decompositora, acumulando grande quantidade de material semidecomposto. Em contraste, o fundo de vale exibe um estoque de serapilheira delgado como reflexo da ação decompositora mais eficiente, onde há pouco acumulo de material semidecomposto. Como resultado do acúmulo de matéria orgânica semidecomposta no Divisor de Drenagem, seu solo exibe maior acidez e menor fertilidade efetiva.

\section{Agradecimentos}

À CAPES, à FAPERJ e ao ICNT-ReaGeo/CNPq pelos financiamentos concedidos. Ao Biólogo Marcelo Vicente pela contribuição acadêmica e de campo. À equipe do PARNA-Tijuca pelo apoio logístico aos trabalhos de campo. Ao Professor do departamento de Geografia da UFRJ Dr. Evaristo de Castro Jr. (in memorian).

\section{Referência Bibliográficas}

ABDOLALAHI, L.; SCHJØNNING, P.; ELMHOLT, S.; MUNKHOLM, L. J, The effects of organic matter application and intensive tillage and traffic on soil structure formation and stability. Soil \& Tillage Research, v. 136, p. 28-37, 2014. DOI: 10.1016/j.still.2013.09.011

CAMINO-SERRANO, M.; GIELEN, B.; LUYSSAERT, S.; CIAIS, P.; SARA VICCA, S.; GUENET, B.; VOS, B.; COOLS, N.; AHRENS, B.; ARAIN, M.A.; WERNER BORKEN, M.; CLARKE, N.; CLARKSON, B.; CUMMINS, T.; DON, A.; PANNATIER, E.G.; LAUDON, H.; MOORE, T.; NIEMINEN, T.M.; NILSSON, M.B.; MATTHIAS PEICHL, M.; SCHWENDENMANN, L.; SIEMENS, J.; JANSSENS, I. Linking variability in soil solution dissolved organic carbon to climate, soil type, and vegetation type. Global Biogeochemical
Cycles, v. 28, p. 497-509. 2014. DOI: 10.1002/2013GB004726

CAPOANE, V.; KROLOW, I.R.C.; SANTOS, D.R.; SANTOS, L.J.C.; TROIAN, A. Distribuição espacial do fósforo disponível do solo em uma bacia hidrográfica agrícola e sua relação com os fatores ambientais uso da terra e declividade. Revista Brasileira de Geomorfologia, v. 17, n. 4, 2016. DOI: 10.20502/ rbg.v17i4.976

CARVALHO, D. A. DE.; OLIVEIRA-FILHO, A. T.; VAN DEN BERG, E.; FONTES, M. A. L.; VILELA, E. A.; SÁ, J. J. G. \& CARVALHO, W. A. C. Variações florísticas e estruturais do componente arbóreo de uma floresta ombrófila alto-montana às margens do rio Grande, Bocaina de Minas, MG, Brasil. Acta Botanica Brasilica, v. 19, n. 1, p. 91-109. 2005. DOI: 10.1590/ S0102-33062005000100010

CHELLAIAH, D.; YULE, C.M. Litter decomposition is driven by microbes and is more influenced by litter quality than environmental conditions in oil palm streams with different riparian types. Aquatic Sciences, v. 80, ref. 43, 2018. DOI: 10.1007/s00027-018-0595-y

COELHO NETTO, A.L. Overlandflow production in a tropical rainforest catchment: the role of litter cover. Catena, v. 14, p. 213-231, 1987. DOI: 10.1007/s00027-018-0595-y

DIAS, M.A.; COELHO NETTO, A.N. A influência da topografia na distribuição de gramíneas em um fragmento de Floresta Atlântica urbana montanhosa - Maciço da Tijuca/RJ. Revista Brasileira de Geomorfologia, v. 12, n. 2, p. 03-14, 2011. DOI: 10.20502/rbg.v12i2

DICK, G.; SCHUMACHER, M.V. Relações entre solo e fitofisionomias em florestas naturais. Ecologia e Nutrição Florestal, v. 3,n. 2,p. 31-39, 2015.DOI: 10.5902/2316980X16741

DRUMOND, J.A. O jardim dentro da máquina: breve história ambiental da Floresta da Tijuca. Estudos Histórico, v. 1, p. 276-298, 1988.

EMBRAPA (1997) Manual de métodos de análise do solo. Publicação EMBRAPA, 2a Ed. Rio de Janeiro, 212p.

FAHNESTOCK, J.T.; POVIRK, K.L.; WELKER, J.M. Ecological significance of litter redistribution by wind and snow in arctic landscapes. Ecography, v. 23, p. 623-631, 2000. DOI: 10.1111/j.1600-0587.2000.tb00181.x

FERNANDES, M. C.; AVELAR, A. S.; COELHO NETTO, A. N., Domínios Geo-Hidroecológicos do Maciço da Tijuca, RJ: Subsídios ao Entendimento dos Processos Hidrológicos e Erosivos. Anuário do instituto de Geociências - UFRJ, v. 29, n. 2, p. 122-148, 2006. 
FIGUEIRÓ, A.S., COElho NETTO, A.L. Análise da variabilidade térmica em zonas de bordas florestais com interface urbana no maciço da Tijuca, Rio de Janeiro-RJ. Ciência e Natura, v. 29, n. 2, p. 173-186, 2007. DOI: 10.5902/2179460X9892

FLOR, I. C.; SANTOS, R.; HARTER-MARQUES, B., Litterfall at different successional stages in a tropical rain forest in southern Brazil. Ciência e Natura, v. 39, n. 3, p. 494-502, 2017. DOI: 10.5902/2179460X26019

GARAY, I.; KINDEL, A.; CARNEIRO, R.; FRANCO, A.A.; BARROS, E.; ABBADIE, L. Comparação da matéria orgânica e de outros atributos do solo entre plantações de Acacia mangium e Eucalyptus grandis. Revista Brasileira de Ciências do Solo, v. 27, p. 705-712, 2003. DOI: 10.1590/S0100-06832003000400015

GOLLEY, F. B. Tropical rain forest ecosystems: structure and function. Amsterdam: Elsevier, 392p, 1983.

GOTELLI, N. J. e ELLISON, A. M. Princípios de estatística em ecologia. Ed. Artmed, RS, 527p, 2011.

GUEDES, J.; KRUPEK, R.A. Florística e fitossociologia do componente arbóreo de um fragmento de floresta ombrófila densa do estado de São Paulo. Acta Biológica Catarinense, v. 3, n. 1, p. 12-24, 2016. DOI: 10.21726/abc.v3i1.184

GUEDES-BRUNI, R. R. Composição, estrutura e similaridade florística de dossel em seis unidades fisionômica de Mata Atlântica no Rio de Janeiro. Tese de Doutorado. Universidade de São Paulo, São Paulo, 206p. 1998.

GURTZ, M.E.; MARZOLF, G.R.; KILLINGBECKR, K.T.; DAVID L. SMITH, D.L.; MCARTHUR, J.V. Hydrologic and Riparian Influences on the Import and Storage of Coarse Particu ate Organic Matter in a Prairie Stream. Canadian Journal of Fisheries and Aquatic Sciences, v. 45, p. 655-665, 1988. DOI: 10.1139/f88-079

Herwitz, S. R.; Young, S. S. Mortality, recruitment, and growth rates of montane tropical rain forest canopy trees on Mount Bellenden-Ker, northeast Queensland, Australia. Biotropica v. 26, p. $350-361,1994$. DOI: $10.2307 / 2389228$

HIGUCHI, P.; SILVA, A.C.; FERREIRA, T.S.; SOUZA, S.T.; GOMES, J.P.; SILVA, K.M.; SANTOS, K.F.; LINKE, C.; PAULINO, P.S. Influência de variáveis ambientais sobre o padrão estrutural e florístico do componente arbóreo, em um fragmento de Floresta Ombrófila Mista Montana em Lages, SC. Ciência Florestal, v. 22, n. 1, p.79-90, 2012. DOI: 10.5902/198050985081

KINDEL, A.; GARAY, I. Caracterização de ecossistemas da Mata Atlântica de Tabuleiros por meio das formas de húmus. R.
Brasileira de Ciências do Solo, v. 25, p. 551-563, 2001. DOI: 10.1590/S0100-06832001000300004

LIMA, R.B.A.; SILVA, R.K.S.; PAULA, M.D.; GUIMARÃES, E.T.R.; BRAGA, E.C.B. Estrutura fitossociológica e diamétrica de um fragmento de Mata Atlântica, Pernambuco, Brasil. Revista Desafios, v. 4, n. 4, 2017. DOI: 10.20873/uft.2359$3652.2017 \mathrm{v} 4 \mathrm{n} 4 \mathrm{p} 143$

MAÇANEIRO, J.P. OLIVEIRA, L.Z.; SEUBERT, R.C.; EISENLOHR, P.V.; SCHORN, L.A. More than environmental control at local scales: do spatial processes play an important role in floristic variation in subtropical forests? Acta Botanica Brasilica, v. 30, n. 2, p. 183-192, 2016. DOI: 10.1590/0102$33062015 \mathrm{abb} 0294$

MARCOS, C.S.; MATOS, D.M.S. Estrutura de populações de palmiteiro (Euterpe edulis Mart.) em áreas com diferentes graus de impactação na Floresta Da Tijuca, RJ. Floresta e Ambiente, v. 10, n. 1, p. 27-37, 2003.

MONTEZUMA, R. C. M. Produção e reabilitação funcional do piso florestal em clareira de deslizamento, Parque Nacional da Tijuca, RJ. Tese (doutorado em Geografia), Instituto de Geociências, Universidade Federal do Rio de Janeiro, 294 p, 2005.

MIRANDA, F.S.M.; BARBOSA, L.S.; CASTRO JUNIOR, E.; AVELAR, A.S. Estrutura da vegetação condicionada por fatores topográficos em floresta de encosta no PARNA - Tijuca, RJ. Revista Geonorte, v. 5, n. 23, p. 349-353, 2014.

MIRANDA, F. S. M.; AVELAR, A. S., Dinâmica de carbono orgânico dissolvido em ecossistemas florestais: uma revisão sobre a lixiviação pela chuva. Revista Brasileira de Geografia Física, v. 11, n. 7, p. 2351-2374. 2018. DOI: 10.26848/rbgf. v11.07.p2351-2374

MUNHOZ, R. E. F., ALMEIDA, P., NEGRI, F., RODRIGUES, G., CAPELLARI, L., MELLO, J. C. P. Quebra de dormência em Palmito Juçara (Euterpe edulis). Revista Uningá, v. 5, n. 1, p. 163-169, 2005.

NEGREIROS, A.B.; COELHO NETTO, A.N. Reabilitação funcional de clareira de deslizamento em encosta íngreme no domínio da floresta atlântica, Rio de Janeiro (RJ). Revista Brasileira de Geomorfologia, v. 10, n. 1, p.85-93, 2009. DOI: 10.20502/rbg.v10i1.120

OLIVEIRA, R.R.; ZAÚ, A.S.; SILVA, D.F.; VIANNA, M.C.; SODRÉ, D.O.; SAMPAIO, P.D. Significado ecológico da orientação de encostas do Maciço da Tijuca, Rio de Janeiro. Oecologia Brasilienses, v. 1, p. 523-541, 1995. 
OLIVEIRA, R. R.; LACERDA, L. D. Contaminação por chumbo na serapilheira do Parque Nacional da Tijuca - RJ. Act. Bot. Bras. v. 2, p. 165-169. 1987. DOI:10.1590/S010233061987000300016

OLSON, J.S. Energy storage and the balance of producers and decomposers in ecological systems. Ecology, v. 44. p. 322-331, 1963. DOI: $10.2307 / 1932179$

ORNDORFF, K.A.; LANG, G.E. Leaf litter redistribution in a west Virginia Hardwood Forest. Journal of Ecology, v. 69, p. 225-235, 1981. DOI: $10.2307 / 2259827$

PESSOA, F. A.; CESÁRIO, F. V.; CASTRO JÚNIOR, E. A utilização de características químicas do solo na análise funcional ecossistêmica de fragmentos florestais: estudo de caso na bacia hidrográfica do bonfim, região serrana do Rio de Janeiro. Revista Geonorte, v. 3, n. 4, p. 402-414. 2012.

RODRIGUES, A.L; WATZLAWICK, L.F.; GENÚ, A.M.; HESS, A.F.; EBLING, A.A. Atributos de um solo florestal em uma topossequência e relações com a comunidade arbórea. Revista Floresta, v. 46, n. 2, p.145-154, 2016. DOI: 10.5380/rf.v46i2.36219

SALES, G.P.S.; GUEDES-BRUNI, R.R. Um quebra-cabeça verde: "montando as peças" do reflorestamento empreendido na Floresta da Tijuca. In: VIII Simpósio Nacional de Ciência e Meio Ambiente (SNCMA), 8, 2017. Anápolis. Anais... SOLCHA, p. 01-19, ISSN: 2179-5193.

SANTOS, R. S.; BARRETO-GARCIA, P. A. B.; SCORIZA, R. N. Fungos micorrízicos arbusculares e serapilheira como indicadores do efeito de borda em fragmento de floresta estacional. Ciência Florestal, v. 28, n. 1, p. 324-335. 2018. DOI: $10.5902 / 1980509831603$

SARAIVA, A.C.R.; FISCH, S.T.V.; TOLEDO, M.C.B. Influências edáfica e topográfica sobre a comunidade de palmeiras da floresta ombrófila densa Montana, Parque Estadual da Serra do Mar-SP, Brasil. Revista Ambiente Água v. 11, p. 1190-1206, 2016. DOI:10.4136/ambi-agua.1921

SEEKELL, D.A., LAPIERRE, J.F., ASK, J., BERGSTRÖM, A.K., DEININGER, A., RODRÍGUEZ, P., KARLSSON, J., The influence of dissolved organic carbon on primary production in northern lakes. Limnology and Oceanography v. 60, p. 1276-1285. 2015. DOI:10.1002/lno.10096

SIEFERT, C.A.C.; SANTOS, I. Dinâmica do carbono orgânico e processos hidrológicos na escala da bacia hidrográfica: uma revisão. Revista Brasileira de Geomorfologia, v. 19, n. 1, p. 3-16, 2018. DOI: 10.20502/rbg.v19i1.1248

SILVA, L.C.; ARAÚJO, E.J.G.; CURTO, R.A.; NASCIMENTO,
A.M.; ATAÍDE, D.H.S.; MORAIS, V.A. Estoques de biomassa e carbono em unidade de conservação no bioma Mata Atlântica. BIOFIX Scientific Journal, v. 3 n. 2 p. 243-25, 2018. DOI: 10.5380/biofix.v3i2.59592

SWIFT, M. J., HEAL, O.W. \& ANDESON, J. M., Decomposition in Terrestrial Ecossystems. University of California Press, Berkley, Los Angeles, 1979. 327p.

STEFANI, E.J.F. Dinâmica do carbono, produção e decomposição de serapilheira, estoque e produção de raiz fina na Floresta Ombrófila Densa Atlântica no Parque Estadual da Serra do Mar. Tese (Doutorado em Biologia Vegetal) Instituto de Biologia, Universidade Estadual de Campinas, 2017.

TONIN, A.M.; JOSÉ F. GONÇALVES JR., J.F.; BAMBI, P.; SHEYLA R. M. COUCEIRO, S.R.M.; FEITOZA, L.A.M.; FONTANA, L.E.; HAMADA, N.; HEPP, L.U.; LEZANKOWALCZUK, V.G.; LEITE, G.F.M.; LEMES-SILVA, A.L.; LISBOA, L.K.; LOUREIRO, R.C.; MARTINS, R.T.; MEDEIROS, A.O.; MORAIS, P.B.; MORETTO, Y.; OLIVERIA, P.C.A.; PEREIRA, E.B.; FERREIRA, L.P.; PÉREZ, J.; PETRUCIO, M.M.; REIS, D.F; REZENDE, R.S.; ROQUE, N.; SANTOS, L.E.P.; SIEGLOCH, A.E.; TONELLO, G.; BOYERO, L. Plant litter dynamics in the foreststream interface: precipitation is a major control across tropical biomes. Scientific Reports, v. 7. 2017. DOI:10.1038/s41598-017-10576-8

VIOLITA; KOTOWSKA, M.M.; HERTEL, D.; TRIADIATI; MIFTAHUDIN; ANAS, I. Transformation of lowland rainforest into oil palm plantations results in changes of leaf litter production and decomposition in Sumatra, Indonesia. Journal of Biodiversity and Environmental Sciences, v. 6, n. 1, p. 546-556, 2015.

WERNER, F.A; HOMEIER, J. Is tropical montane forest heterogeneity promoted by a resource-driven feedback cycle? Evidence from nutrient relations, herbivory and litter decomposition along a topographical gradiente. Functional Ecology, v. 29, p. 430-440, 2015. DOI: 10.1111/13652435.12351

YE, L., WU, X., LIU, B., YAN, D., KONG, F. Dynamics and sources of dissolved organic carbon during phytoplankton bloom in hypereutrophic Lake Taihu (China). Limnologica - Ecology and Management of Inland Waters v. 54, p. 5-13, 2015. DOI: 10.1016/j.limno.2015.05.003

YAN, Y.; XIN, X.; XU, X.; WANG, X.; YAN, R.; MURRAY, P.J. Vegetation patches increase wind-blown litter accumulation in a semi-arid steppe of northern China. Environmental Research Letters, v. 11. 2016. DOI: 10.1088/1748-9326/11/12/124008 